\title{
Species specificity of $\mathbf{0}$-linked carbohydrate chains of the oviducal mucins in amphibians: structural analysis of neutral oligosaccharide alditols released by reductive $\beta$-elimination from the egg-jelly coats of Rana clamitans ${ }^{1}$
}

\author{
Florence DELPLACE, Emmanuel MAES, Jérôme LEMOINE and Gérard STRECKER ${ }^{2}$ \\ Laboratoire de Glycobiologie Structurale et Fonctionnelle, Unité Mixte de Recherche du CNRS 8576, Université des Sciences et Technologies de Lille, 59655 Villeneuve \\ d'Ascq cedex, France
}

\begin{abstract}
The extracellular matrix (the so-called jelly coat) surrounding amphibian eggs mainly comprises highly O-glycosylated proteins. These oviducal mucins have an important role in the fertilization process, and their carbohydrate chains are remarkably speciesspecific. Alkaline reductive treatment of the jelly-coat material of the frog Rana clamitans led to the release of oligosaccharide alditols. The neutral oligosaccharide alditols were fractionated and purified by successive chromatographic techniques. The structures of 27 of them, ranging from three to sixteen monosaccharides, were established by a combination of NMR spectroscopy, methylation analyses and matrix-assisted laser-desorption ionization-time of flight MS. Typically, some of the neutral compounds appeared to possess the core structure:
\end{abstract}

$\operatorname{Gal}(\beta 1-3)[\operatorname{GlcNAc}(\beta 1-6)] \operatorname{Gal}(\beta 1-3)[\operatorname{GlcNAc}(\beta 1-6)] \operatorname{GalNAc}-$ ol (where GalNAc-ol represents $N$-acetylgalactosaminitol). Moreover, a novel type of chain termination, characterized by an unusual sequence $\{\operatorname{Fuc}(\alpha 1-2) \operatorname{Gal}(\alpha 1-3) \operatorname{Gal}(\alpha 1-4) \operatorname{Gal}(\beta 1-3 / 4)\}$ was observed. Indeed, the most complex representative structure of this series was found to be: $\operatorname{Fuc}(\alpha 1-2) \mathrm{Gal}(\alpha 1-3) \mathrm{Gal}(\alpha 1-4)$ $\operatorname{Gal}(\beta 1-3)[\operatorname{Fuc}(\alpha 1-2) \operatorname{Gal}(\alpha 1-3) \operatorname{Gal}(\alpha 1-4) \operatorname{Gal}(\beta 1-4) \operatorname{GlcNAc}$ $(\beta 1-6)] \operatorname{Gal}(\beta 1-3)[\operatorname{Fuc}(\alpha 1-2) \operatorname{Gal}(\alpha 1-3) \operatorname{Gal}(\alpha 1-4) \operatorname{Gal}(\beta 1-4)-$ $\operatorname{GlcNAc}(\beta 1-6)]$ GalNAc-ol.

Key words: glycosylation, NMR spectroscopy, O-glycans, oligosaccharides.

\section{INTRODUCTION}

Amphibian eggs are surrounded by a vitellin envelope and several structurally and chemically distinct jelly coats. Jelly-coat layers are synthesized by specific regions of the oviduct, and are sequentially deposited around the oocyte. This jelly coat is the first barrier through which fertilizing sperm must pass before reaching the egg plasma membrane. The jelly coats are made up of several concentric layers of distinct composition and morphology, which can vary widely between species. Mucin-type glycoproteins, highly O-glycosylated, have been shown to be the major components of this jelly coat and to have important roles in fertilization. Many functions have been attributed to the egg jelly components such as sperm binding, sperm capacitation, induction of the acrosome reaction, prevention of species crossfertilization, block of polyspermy (anurans) and provision of a protective ionic environment for the developing embryo [1-10]. A major glycoprotein from the egg jelly coat of Bufo japonicus has been isolated, and was shown to display calcium-binding properties [7]. The isolation and characterization of two highly glycosylated proteins from Bufo arenarum egg jelly coat, which contribute towards forming the jelly layers, has been reported [11]. However, the molecular mechanisms underlying such functions are not yet well characterized.

Previous studies have shown a species-specific structural diversity in carbohydrate chains of amphibian egg jelly coats [12-19]. These carbohydrate chains, which represent new pheno- typic markers of amphibian species, could be involved in speciesspecific gamete recognition, or in specific host-parasite interaction [20].

A block to cross-fertilization located in the egg jelly of the frog Rana clamitans has been observed [21]. If the specificity resides in the jelly, then a study of the exact chemical composition of the molecules would help to elucidate the mechanism of jelly action in fertilization.

In the present study, we have isolated carbohydrate chains from the oviducal mucins of $R$. clamitans and we describe the primary structure of neutral oligosaccharide alditols, which appear to be specific for this species.

\section{EXPERIMENTAL}

\section{Sampling of jelly-coat mucus}

Eggs from $R$. clamitans were obtained from Amphibians of North America, Charles D. Sullivan Company, Inc. (Nashville, TN, U.S.A.). The jelly-coat material was freeze-dried.

\section{Isolation of oligosaccharide alditols}

O-linked oligosaccharides were released from the crude material by alkaline borohydride treatment $\left(1 \mathrm{M} \mathrm{NaBH}_{4}, 0.1 \mathrm{M} \mathrm{NaOH}\right)$ at $37^{\circ} \mathrm{C}$ for $72 \mathrm{~h}$. The reaction was stopped by the addition of DOWEX $50 \times 8\left(25-50\right.$ mesh; $\mathrm{H}^{+}$form $)$at $4{ }^{\circ} \mathrm{C}$. The solution

Abbreviations used: HMQC, heteronuclear multiple-quantum coherence; HMBC, heteronuclear multiple-bound coherence; Le ${ }^{x}$, Lewis X; ROESY, rotating-frame nuclear Overhauser enhancement spectroscopy; MALDI-TOF, matrix-assisted laser-desorption ionization-time of flight; GalNAc-ol, $N$ acetylgalactosaminitol.

1 We would like to dedicate this paper to the memory of Professor André Verbert.

2 To whom correspondence should be addressed (e-mail gerard.strecker@univ-lille1.fr). 
was filtered, adjusted to $\mathrm{pH} 6.5$, and then concentrated under vacuum at $25^{\circ} \mathrm{C}$. Borate salts were removed by repeated evaporation with methanol. The resulting sample was applied to a Bio-Gel P-2 (Bio-Rad Laboratories, Richmond, VA, U.S.A.) column and eluted with water. The carbohydrate-containing fractions were revealed with orcinol/sulphuric acid reagent $[0.2 \%$ (w/v) orcinol in $\mathrm{H}_{2} \mathrm{SO}_{4}$ /water; $1: 4,(\mathrm{v} / \mathrm{v})$ ] on silica-gel plates (pre-coated silica gel 60; Merck, Gibbstown, NJ, U.S.A.), pooled and concentrated in a rotary evaporator.

Residual peptide material was removed on a column of DOWEX $50 \times 2\left(200-400\right.$ mesh; $\mathrm{H}^{+}$form). Oligosaccharide alditols were applied on a column of DOWEX $1 \times 2(200-400$ mesh; HCOO form). The major fraction, containing neutral oligosaccharide alditols, was obtained after elution with water. Acidic oligosaccharide alditols were also obtained by elution with a discontinuous gradient $(50,100,200,500 \mathrm{mM})$ of pyridine/acetic acid solution, and desalting by gel filtration on a Bio-Gel P-2 column.

Five fractions (termed FN A to FN E) were obtained from the major neutral sample after gel-filtration chromatography on a Bio-Gel P-6 column. These five fractions were separated on the basis of their behaviour upon TLC on silica-gel plates in the solvent system n-butanol/acetic acid/water (20:10:15, by vol.). Oligosaccharide alditols from the fractions FN B, FN C and FN D were isolated by HPLC on a primary amine-bonded silica column (Supelcosyl ${ }^{\mathrm{TM}} \mathrm{LC}-\mathrm{NH} 2 ; 4.6 \mathrm{~mm} \times 250 \mathrm{~mm}$; Supelco Inc., Bellefonte, PA, U.S.A.) using acetonitrile/water gradients with a flow rate of $1 \mathrm{ml} / \mathrm{min}$ at room temperature. Oligosaccharide peaks were detected by absorption at $206 \mathrm{~nm}$. After evaporation of acetonitrile under vacuum, the fractions were desalted on a Bio-Gel P-2 column and freeze-dried.

Fractions C5, C8, C10, C11, C15 and C17 were fractionated further by $\mathrm{C}_{18}$ reverse-phase chromatography on a $5 \mu \mathrm{m}$ Zorbax ODS column $(4.6 \mathrm{~mm} \times 250 \mathrm{~mm})$ run isocratically with water as an eluent at a flow rate of $0.5 \mathrm{ml} / \mathrm{min}$ at room temperature.

\section{Analytical procedures}

Carbohydrate analyses were performed using GC. Samples were analysed after methanolysis $(0.5 \mathrm{M} \mathrm{HCl}$ in anhydrous methanol for $24 \mathrm{~h}$ at $80^{\circ} \mathrm{C}$ ) followed by $\mathrm{N}$-reacetylation and trimethylsilylation as described by Kamerling et al. [22].

Methylation analyses were performed as described by Ciucanu and Kerek [23]. The partially acetylated methyl glycosides were analysed by GC/MS on a Carlo Erba GC 8000 gas chromatograph coupled with a Finnigan Automass II mass spectrometer, and identified as described by Fournet et al. [24]. MS analyses were performed in electron-impact or chemical-ionization mode using $\mathrm{NH}_{3}$ as the reactant gas.

NMR experiments were performed using a Bruker ${ }^{\mathrm{TM}}$ ASX 400 WB spectrometer. Chemical shifts are expressed in p.p.m. downfield from internal sodium 4,4'-dimethyl-4-silapentane-1sulphonate, but were actually measured by reference to internal acetone $\left(\delta=2.225\right.$ p.p.m. in ${ }^{2} \mathrm{H}_{2} \mathrm{O}$ at $\left.25^{\circ} \mathrm{C}\right)$. The twodimensional homonuclear COSY, with simple- and double-relay transfer, the heteronuclear multiple quantum coherence (HMQC), the heteronuclear multiple bound coherence (HMBC) and the rotating-frame nuclear Overhauser enhancement spectroscopy (ROESY) experiments were performed using Bruker standard-pulse sequences.

Molecular mass of the oligosaccharide alditols was measured by matrix-assisted laser desorption-ionization-time-of-flight (MALDI-TOF) MS on a Vision 2000 TOF instrument (Thermo Finnigan France, Les Ulis, France) in the reflectron mode (nitrogen laser: $337 \mathrm{~nm}$ ).
Samples were dissolved in water at a concentration of 50 $100 \mathrm{pmol} / \mu 1$. Of the sample solution, $1 \mu 1$ was mixed with an equal volume of the matrix solution on the target, and then allowed to crystallize at room temperature. Neutral structures were analysed in the positive mode using 2,5-dihydroxybenzoic acid $[10 \mathrm{mg} / \mathrm{ml}$ in methanol/water; 70:30, (v/v)]. External calibration was performed using an angiotensin I standard purchased from Sigma (molecular mass, 1296.7 Da). Between 10 and 25 shots were accumulated for each spectrum.

In order to complete its analysis, a periodic oxidation $/ \mathrm{NaBH}_{4}$ reduction procedure was applied to compound B1. Oxidation with $\mathrm{NaIO}_{4}$ was performed in $0.01 \mathrm{M}$ sodium acetate buffer, $\mathrm{pH}$ 4.5 , at $4{ }^{\circ} \mathrm{C}$ for $30 \mathrm{~min}$. The reaction was quenched by the addition of ethylene glycol, and the mixture was then adjusted to $\mathrm{pH} 9$ before reduction by $\mathrm{NaBH}_{4}$ for $3 \mathrm{~h}$ at room temperature. The reaction was then stopped by acetic acid addition, and the mixture was purified by repeated evaporation with methanol and desalting on a Bio-Gel P-2 column. The resulting sample was finally analysed by MALDI-TOF spectrometry in the positive mode, as described for neutral structures.

\section{RESULTS}

\section{Isolation of neutral oligosaccharide alditols}

The jelly-coat material of $R$. clamitans was submitted to alkaline borohydride degradation, and the released oligosaccharides were desalted by gel-filtration chromatography. The pool of released O-linked carbohydrate chains was submitted to a cationicexchange chromatography procedure to remove residual peptides. Neutral oligosaccharide alditols were then separated from acidic oligosaccharide alditols by anionic-exchange chromatography on DOWEX $1 \times 2$, HCOO form. After water elution of neutral compounds, which constitute the major fraction of the isolated oligosaccharide alditols, acidic oligosaccharide alditols were desorbed with a discontinuous gradient of pyridine/ acetate solution. These acidic compounds will be the subject of a subsequent study.

The fractionation by gel filtration on a Bio-Gel P-6 column of the neutral pool gave five fractions, namely FN A to FN E. These fractions differ in terms of their migration behaviour during TLC analysis, indicating different sizes in the oligosaccharides present in each fraction. The fraction $\mathbf{F N} \mathbf{A}$, which did not migrate, and the fraction $\mathbf{F N} \mathbf{E}$, which contains only small components, were not analysed. The fractions of medium size, FN B to FN D, were investigated.

HPLC on a primary-amine-bonded silica column was used to fractionate FN B into four oligosaccharide alditol fractions (B1 to B4), FN C into 19 oligosaccharide alditol fractions (C1 to C19) and FN D into six oligosaccharide alditol fractions (D1 to D6), as shown in Figure 1. All the collected fractions were purified by gel filtration on Bio-Gel P-2 before structural elucidation. HPLC on a $\mathrm{C}_{18}$ reverse-phase Zorbax column was used to sub-fractionate several FN C fractions: C5, C8, C10, C11, C15 and C17. Elution was performed isocratically with water (Figure 2).

The compounds $\mathbf{C 1}$ and $\mathbf{C 5 - 2}$ isolated from FN C were also present in FN D, as peaks D2 and D5 respectively. Similarly, the compounds B1 and B2 obtained from FN B corresponded respectively to peaks $\mathbf{C 1 8}$ and $\mathbf{C 1 9}$ of FN C. Certain fractions were complex mixtures, and were not characterized.

\section{Structural determination of neutral oligosaccharide alditols}

The primary structures of the neutral oligosaccharide alditols obtained from oviducal mucins of $R$. clamitans were established 

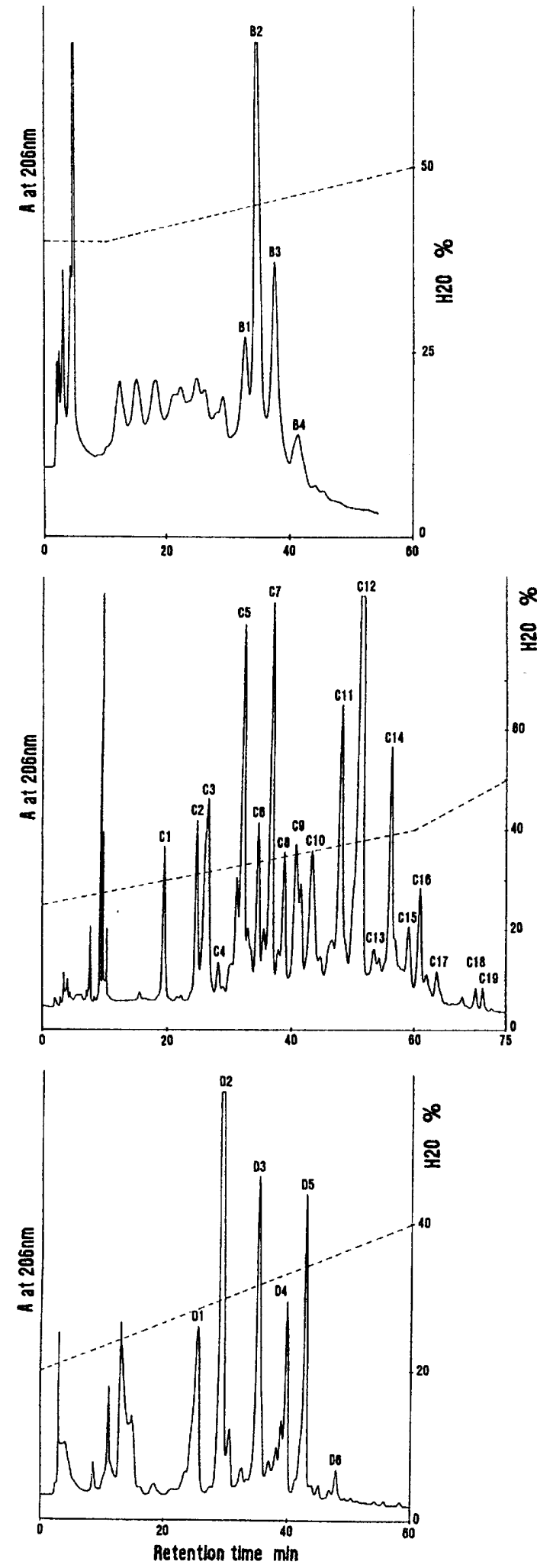

Figure 1 HPLC profiles of oligosaccharide-alditols from the fractions FN B, FN C and FN D

Samples were chromatographed on an $\mathrm{LC}-\mathrm{NH}_{2}$ column eluted with an acetonitrile/water gradient. The flow rate was $1 \mathrm{ml} / \mathrm{min}$. Absorbance was measured at $206 \mathrm{~nm}$. The first peaks of FN B, eluted between 10 and 30 min, were pooled for recycling and ulterior analysis.
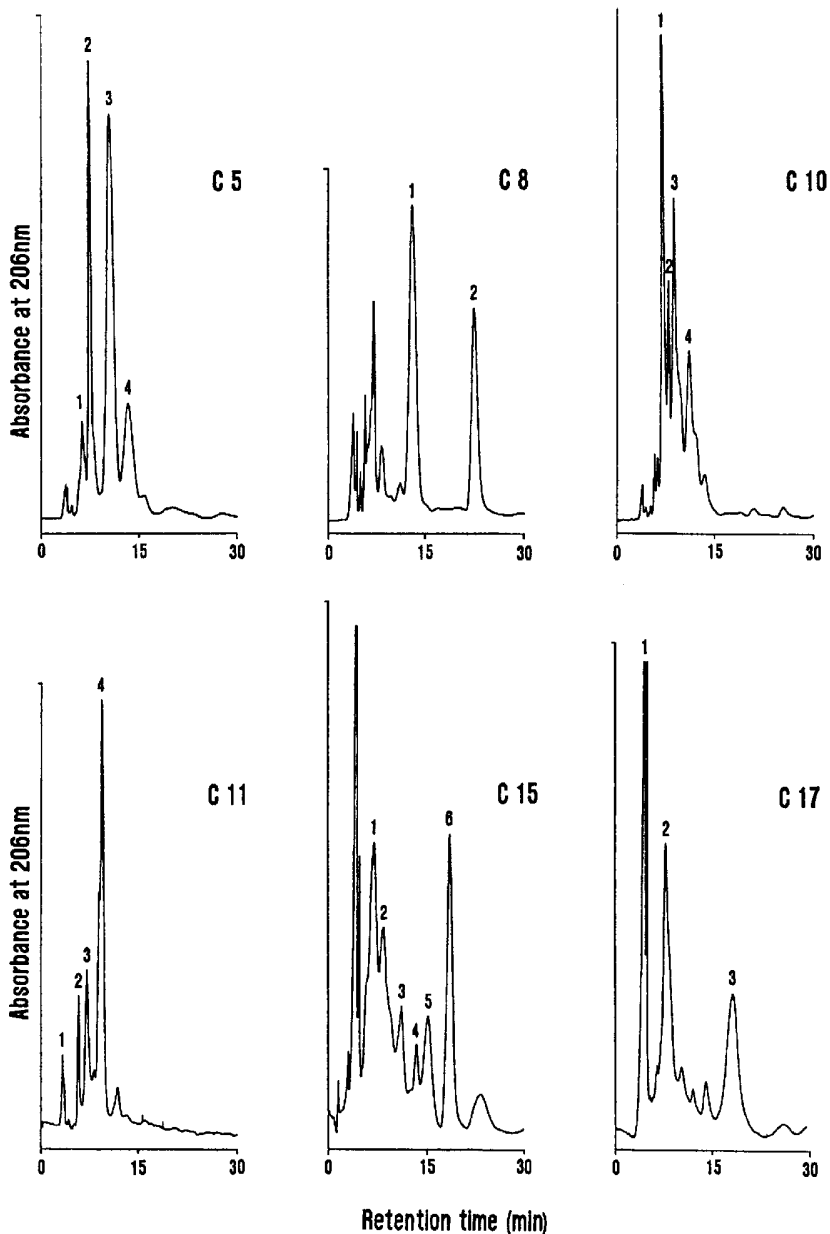

Figure 2 HPLC profiles of oligosaccharide alditols from the fractions C5, C8, C10, C11, C15 and C17, chromatographed on a Zorbax ODS column eluted isocratically with water

The flow rate was $0.5 \mathrm{ml} / \mathrm{min}$. Absorbance was measured at $206 \mathrm{~nm}$.

by combining the results of ${ }^{1} \mathrm{H} /{ }^{13} \mathrm{C}-\mathrm{NMR}$ spectroscopies, methylation analysis and MALDI-TOF analysis.

The structures of all the compounds discussed below are shown in Schemes 1 and 2. The oligosaccharide alditols have been gathered in three main series according to their structural patterns. The numbering of sugar units (roman numerals I to IX and $\mathrm{II}^{\prime}$ to $\mathrm{V}^{\prime}$ ) is exemplified by the structures of compounds presented in NMR spectra (C12 and C14) and in Scheme 2 (C53, C5-1, C10-1 and C8-1).

Neutral oligosaccharide alditols were analysed by MALDITOF spectrometry in the positive ion mode. The spectra showed characteristic $[M+\mathrm{Na}]^{+}$pseudomolecular ions (Table 1).

\section{Compounds D3, D5(= C5-2), C8-2, C10-2, C10-3, C11-4 and C12}

Inspection of the integrated $600 \mathrm{MHz}{ }^{1} \mathrm{H}$ NMR spectrum of compound $\mathbf{C 1 2}$ showed resonances attributable to six $\alpha$ - and three $\beta$-linked sugar residues (Scheme 1 and Table 2). These monosaccharides were identified as $\alpha$-fucose $(\mathrm{F}), \alpha$-galactose (III, IV, IV' and $\mathrm{V}^{\prime}$ ), $\beta$-galactose (II, III') and $\beta$ - $N$ acetylglucosamine (II') as a consequence of TOCSY analysis (Figure 3) and one- and two-step relayed COSY spectra (results 


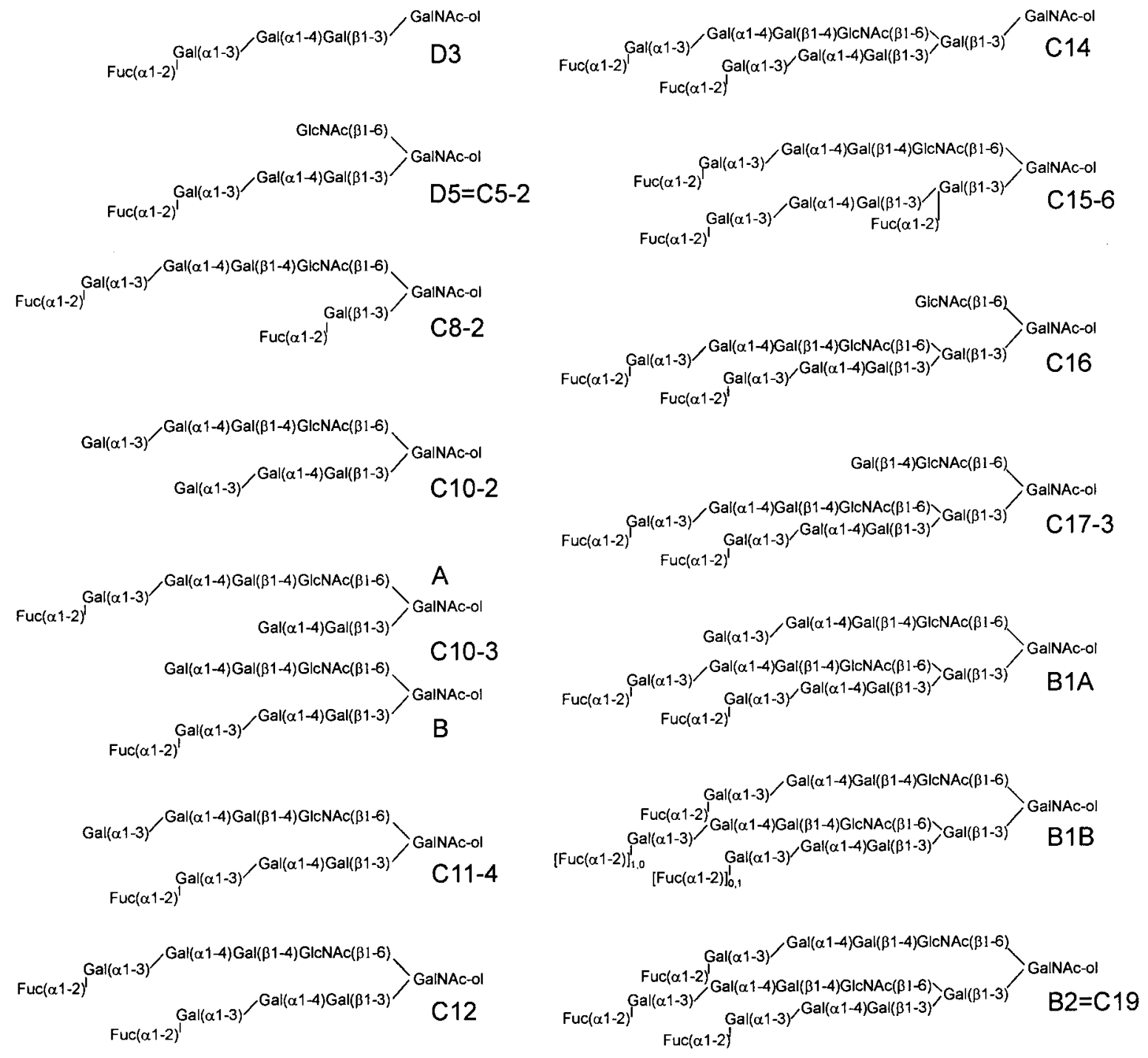

Scheme 1 Structures of neutral oligosaccharide alditols isolated from $R$. clamitans egg jelly coat (first and second series)

not shown), which allowed us to determine the ${ }^{3} J$ coupling constants that are characteristic of the $\beta$-gluco, $\beta$-galacto and $\alpha$ galacto configurations. Moreover, the TOCSY experiment of C12 permitted the assignment of most of the proton resonances (except the H-5 and H-6,6' belonging to the $\beta$-Gal units) and the HMQC experiment allowed the ${ }^{13} \mathrm{C}$ assignments to be made (Figure 3 and Table 2). The $\mathrm{H}-5$ and $\mathrm{H}-6,6^{\prime}$ resonances of the two $\beta$-Gal units II and III' were assigned in the HMQC spectrum. The identification of the terminal $N$-acetylgalactosaminitol (GalNAc-ol) unit was on the basis of the observation of its eight ${ }^{1} \mathrm{H}$ signals. Particularly, the $\mathrm{H}-3, \mathrm{H}-5, \mathrm{H}-6$ and $\mathrm{H}-\mathrm{6}^{\prime}$ resonances are characteristic of the core type 2 structure $\operatorname{GlcNAc}(\beta 1-6)[\operatorname{Gal}(\beta 1-3)]$ GalNAc-ol [25]. Moreover, the assignment of the most downfield ${ }^{13} \mathrm{C}$ signals indicated their involvement in glycosidic linkages: C-2 for $\alpha$-Gal IV and $\mathrm{V}^{\prime}$; C3 for $\alpha$-Gal III and IV'; C-4 for $\beta$-Gal II and III'; and C-3 and C-6 for GalNAc-ol I. The HMBC experiment optimized for long-range ${ }^{3} J_{\mathrm{C}, \mathrm{H}}$ couplings (Figure 3 ) established the following inter-residue linkages: $\quad \alpha$-Fuc $(1 \rightarrow 2)-\alpha-G a l \quad$ IV, $V^{\prime} ; \quad \alpha$-Gal IV, $V^{\prime}(1 \rightarrow 3)-\alpha$-Gal III,IV'; $\alpha$-Gal III,IV'(1 $\left.\rightarrow 4\right)-\beta$-Gal II,III' $; \beta$ Gal III' $(1 \rightarrow 4)-\beta$-GlcNAc II'; $\beta$-GlcNAc II'(1 $\rightarrow 6)$ GalNAc-ol I and $\beta$-Gal II $(1 \rightarrow 3)$ GalNAc-ol I. On the basis of these data, the structure of compound $\mathbf{C 1 2}$ was fully established. Nevertheless, the exact assignment of atom resonances belonging to $\alpha$-Gal units III and IV', on one hand, and units IV and $\mathrm{V}^{\prime}$, on the other hand, was not deduced from this experimentation, but from the comparison of the NMR spectra of compounds D5, C8-2, C102 and C11-4 (see below).

The two-step relayed COSY spectrum (results not shown) of $\mathbf{D 5}(=\mathbf{C 5 - 2})$ revealed the presence of the trisaccharidic sequence $\operatorname{Fuc}(\alpha 1-2) \operatorname{Gal}(\alpha 1-3) \operatorname{Gal}(\alpha 1-4)$. The structural-reporter groups relative to the GalNAc-ol unit (H-3, H-5, H-6, H-6') are characteristic of the core type 2 structure, $\operatorname{GlcNAc}(\beta 1-6)[\operatorname{Gal}(\beta 1-3)]$ GalNAc-ol [25]. Moreover, the chemical shifts of the H-3 and H-4 atoms of GlcNAc II' are characteristic of a terminal $\beta$-GlcNAc unit. These observations indicate that the trisaccharide $\operatorname{Fuc}(\alpha 1-2) \operatorname{Gal}(\alpha 1-3) \operatorname{Gal}(\alpha 1-4)$ is attached to the $\beta$-Gal II unit.

The second compound C8-2 also showed resonances attributable to the trisaccharidic sequence $\operatorname{Fuc}(\alpha 1-2)$ $\operatorname{Gal}(\alpha 1-3) \mathrm{Gal}(\alpha 1-4)$, and to a core type 2 structure. The presence of a second $\alpha$-1,2-linked fucose unit can lead to two possible 

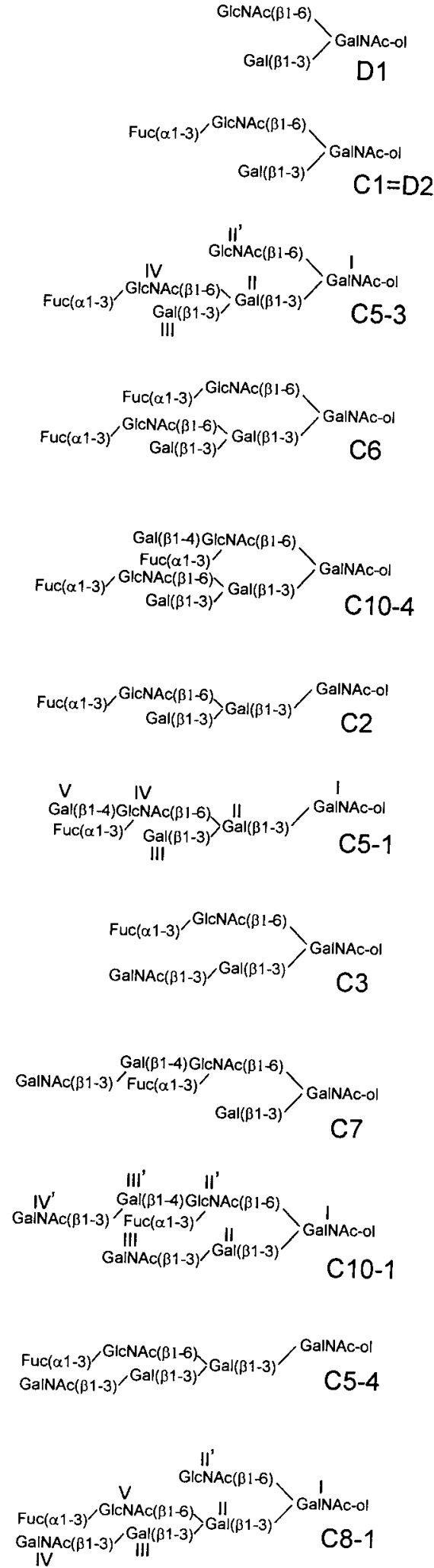

Scheme 2 Structures of neutral oligosaccharide alditols isolated from R. clamitans egg jelly coat (third series)

structures, the first one with a sequence of $\operatorname{Fuc}(\alpha 1-2)$ Gal $\beta-1,3-$ linked to GalNAc-ol, and the second one with the sequence Fuc $(\alpha 1-2) \operatorname{Gal}(\beta 1-4)$ GlcNAc $\beta$-1,6- linked to GalNAc-ol. These sequences have been largely reported in the literature, and are characterized by their Fuc and Gal II or III' H-1 atom resonances. Here, the Gal II and Fuc $\mathrm{F}_{\mathrm{II}} \mathrm{H}-1$ resonances perfectly match those observed for the sequence $\operatorname{Fuc}(\alpha 1-2) \mathrm{Gal}(\beta 1-3) \mathrm{GalNAc}$ ol [25]. These observations confirmed that the $\operatorname{Fuc}(\alpha 1-2)$ $\operatorname{Gal}(\alpha 1-3) \operatorname{Gal}(\alpha 1-4) \operatorname{Gal}(\beta 1-4)$ sequence is attached to the GlcNAc II' unit.

The examination of the COSY spectra of D5 and C8-2 provided some details to allow us to locate the Fuc-Gal-Gal sequence to the upper or the lower branch. Particularly, the H-5 and H-6,6' atom resonances of Gal IV or $\mathrm{V}^{\prime}$ were observed at $\delta=$ 4.227 p.p.m. and 3.76 p.p.m. for D5, and $\delta=4.213$ p.p.m. and 3.744 p.p.m. for C8-2. Since H-4/H-5 cross peaks are generally observable in the case of the $\alpha$-galacto configuration, it became possible to follow these correlations to the anomeric proton via $\mathrm{H}-3$ and $\mathrm{H}-2$.

The COSY spectrum of compound C10-2 (results not shown) indicated the absence of terminal fucose and the presence of two sequences $\operatorname{Gal}(\alpha 1-3) \operatorname{Gal}(\alpha 1-4)$. Since the structural reportergroup signals of the GalNAc-ol unit confirm the nature of the core type 2, the structure of C10-2 is evident. Despite the low resolution of the signals, the $\mathrm{H}-1$ and $\mathrm{H}-2$ of Gal $\mathrm{IV}$ and $\mathrm{V}^{\prime}$ are clearly discernible. Moreover, the $\mathrm{H}-5$ resonance of Gal IV and Gal $\mathrm{V}^{\prime}$ can be easily assigned by comparison with the spectra of D5 and C8-2. The correlations H-5/H-4/H-3 were also observed, but interrupted between $\mathrm{H}-3$ and $\mathrm{H}-2$.

The anomeric protons of Gal IV and $\mathrm{V}^{\prime}$ were finally assigned as a consequence of the inspection of the relayed COSY spectrum of C11-4 (results not shown). The integration of the anomeric region revealed the presence of one $\alpha$-fucose and four $\alpha$-galactose units. Consequently, one $\alpha$-Gal unit occurs in the terminal position, which is confirmed by the upfield value of the $\mathrm{H}-1$ atom of one of the two $\alpha-1,3$-linked galactose units. The location of the fucose unit was deduced from the chemical shift values of the $\mathrm{H}$ 5 and H-6 resonances of the Gal IV and V'. The Gal IV H-5 and H-6,6' signals perfectly match those observed for Gal IV in compound D5, whereas the H-5 and H-6,6' resonances of Gal $\mathrm{V}^{\prime}$ possess new chemical shifts, which result from the loss of the fucose unit. Since the structure of C11-4 is now established, a comparison of the COSY spectra of C11-4 and $\mathbf{C 1 0 - 2}$ allows us to determine the chemical shifts of the Gal IV and $\mathrm{V}^{\prime} \mathrm{H}-2$ and $\mathrm{H}-$ 1 signals. From this comparison, it can be concluded that the signals relative to the $\alpha$-1,3-linked galactose of the 1,3 branch (lower branch) are systematically downfield-shifted with respect to the 1,6 branch (upper branch). This observation led to the complete assignment of the TOCSY spectrum of C12.

The structures of compounds D3 ( $1 \alpha$-Fuc, $2 \alpha$-Gal, $1 \beta$-Gal and 1 GalNAc-ol) and C10-3 (mixture of two isomers: $1 \alpha$-Fuc, $3 \alpha$-Gal, $2 \beta$-Gal, $1 \beta$-GlcNAc and 1 GalNAc-ol) were established by comparison of their COSY spectra (results not shown) with those of the five compounds studied above.

\section{Compounds C14, C15-6, C16, C17-3, B1 $=\mathrm{C} 18)$ and B2 $(=\mathrm{C} 19)$}

This second series of compounds is characterized by the presence of the backbone $\operatorname{Gal}(\beta 1-3) \mathrm{Gal}(\beta 1-3)$ which has been previously characterized in the carbohydrate chains released from the mucins of Bufo bufo [26] and $R$. arvalis [27] (Scheme 1 and Table 3).

The structure of the major compound (C14) of the series was established as a result of the analysis of the two-step relayed COSY and the ROESY spectra (Figure 4). The ${ }^{1} \mathrm{H}-\mathrm{NMR}$ spectrum shows the presence of ten anomeric protons (ratio $2: 2$ : $1: 1: 1: 1: 1: 1)$. As reported above for compound C12, the presence of $2 \alpha$-Fuc, $4 \alpha$-Gal, $3 \beta$-Gal, $1 \beta$-GlcNAc and 1 GalNAcol units was deduced from the measurement of ${ }^{3} J$ coupling 


\section{Table 1 Monosaccharide composition data for neutral oligosaccharide-alditols released from the oviducal mucin of $\boldsymbol{R}$. clamitans}

The compositions of oligosaccharide alditols were deduced from $[\mathrm{M}+\mathrm{Na}]^{+}$pseudomolecular ions obtained by positive-ion MALDI-TOF MS. Monosaccharide units were identified on the basis of their vicinal coupling constants by NMR and of GC carbohydrate analysis after methanolysis and trimethylsilylation. The experimental $[\mathrm{M}+\mathrm{Na}]^{+}$values reported are in agreement with the deduced values calculated from the average masses of native oligosaccharide residues and useful average masses for $\mathrm{O}, \mathrm{H}$ and $\mathrm{Na}$ elements.

\begin{tabular}{|c|c|c|c|c|c|c|c|}
\hline \multirow[b]{2}{*}{ Compound } & \multirow[b]{2}{*}[M+\mathrm{Na}]{$^{+}$Measured value } & \multirow[b]{2}{*}[\mathrm{M}+\mathrm{Na}]{$^{+}$Calculated value } & \multicolumn{5}{|l|}{ Molar ratio } \\
\hline & & & GalNAc-ol & Gal & GlcNAc & GalNAc & Fuc \\
\hline D3 & 879.2 & 878.7 & 1 & 3 & 0 & 0 & 1 \\
\hline $\mathrm{D} 5=\mathrm{C} 5-2$ & 1082.7 & 1081.9 & 1 & 3 & 1 & 0 & 1 \\
\hline C8-2 & 1390.4 & 1390.2 & 1 & 4 & 1 & 0 & 2 \\
\hline $\mathrm{C} 10-2$ & 1422.0 & 1422.2 & 1 & 6 & 1 & 0 & 0 \\
\hline C10-3 A,B & 1406.2 & 1406.2 & 1 & 5 & 1 & 0 & 1 \\
\hline C11-4 & 1568.5 & 1568.4 & 1 & 6 & 1 & 0 & 1 \\
\hline $\mathrm{C} 12$ & 1714.6 & 1714.5 & 1 & 6 & 1 & 0 & 2 \\
\hline C14 & 1876.8 & 1876.6 & 1 & 7 & 1 & 0 & 2 \\
\hline C15-6 & 2023.8 & 2022.8 & 1 & 7 & 1 & 0 & 3 \\
\hline C16 & 2080.3 & 2079.8 & 1 & 7 & 2 & 0 & 2 \\
\hline C17-3 & 2242.7 & 2242.0 & 1 & 8 & 2 & 0 & 2 \\
\hline $\mathrm{B} 1=\mathrm{C} 18$ & 2566.4 & 2566.3 & 1 & 10 & 2 & 0 & 2 \\
\hline $\mathrm{B} 2=\mathrm{C} 19$ & 2712.6 & 2712.4 & 1 & 10 & 2 & 0 & 3 \\
\hline D1 & 611.7 & 611.5 & 1 & 1 & 1 & 0 & 0 \\
\hline $\mathrm{C} 1=\mathrm{D} 2$ & 757.4 & 757.6 & 1 & 1 & 1 & 0 & 1 \\
\hline C5-3 & 1123.6 & 1123.0 & 1 & 2 & 2 & 0 & 1 \\
\hline C6 & 1269.2 & 1269.1 & 1 & 2 & 2 & 0 & 2 \\
\hline C10-4 & 1431.5 & 1431.3 & 1 & 3 & 2 & 0 & 2 \\
\hline $\mathrm{C} 2$ & 919.5 & 919.8 & 1 & 2 & 1 & 0 & 1 \\
\hline C5-1 & 1082.6 & 1081.9 & 1 & 3 & 1 & 0 & 1 \\
\hline C3 & 960.5 & 960.8 & 1 & 1 & 1 & 1 & 1 \\
\hline $\mathrm{C7}$ & 1123.1 & 1123.0 & 1 & 2 & 1 & 1 & 1 \\
\hline C10-1 & 1326.4 & 1326.2 & 1 & 2 & 1 & 2 & 1 \\
\hline C5-4 & 1123.6 & 1123.0 & 1 & 2 & 1 & 1 & 1 \\
\hline C8-1 & 1326.4 & 1326.2 & 1 & 2 & 2 & 1 & 1 \\
\hline
\end{tabular}

constants. The chemical shifts of GalNAc-ol H-6,6', both observed at $\delta \approx 3.67$ p.p.m., are characteristic of core type 1 : Gal $(\beta 1-3)$ GalNAc-ol [25]. A two-dimensional ROESY experiment was used to sequence the oligosaccharide alditol (Figure 4). Starting from the terminal fucose unit, strong inter-residue ROESY cross-peaks were observed between Fuc H-1 and Gal V, IX H-2 (and H-3), Gal V, IX H-1 and Gal IV, VIII H-3 (and H-4), Gal IV H-1 and Gal III H-4, Gal VIII H-1 and Gal VII H-4, Gal III H-1 and Gal II H-3, Gal II H-1 and GalNAc-ol I H-3. Since the expected ROESY contact between GlcNAc H-1 and Gal II H-6 was not observable, the attachment of GlcNAc VI to C-6 of Gal II was verified by methylation analysis, which clearly indicated the presence of 2,4-dimethylgalactose. The other methylation results are in agreement with the conclusions drawn from the ROESY experiment. From these analyses, and particularly from the ROESY spectrum, which indicated the sequence Gal IV $\rightarrow$ Gal III $\rightarrow$ Gal II $\rightarrow$ GalNAc-ol I and Gal VIII $\rightarrow$ Gal VII, it was possible to clearly assign the Gal IV and Gal VIII H-1 resonances.

Compound C16 is characterized by the presence of an additional $\beta$-GlcNAc unit (unit II'), the $\mathrm{H}-3$ and $\mathrm{H}-4$ resonances of which are characteristic of a terminal unit. Moreover, the H-6 and H-6' resonances of GalNAc-ol (at $\delta=3.934$ and 3.692 p.p.m.) clearly show the presence of the core type 2 .

The COSY spectrum of compound $\mathbf{C 1 7 - 3}$ compared with $\mathbf{C 1 6}$ indicates the presence of an additional Gal III' unit, occurring in the terminal position $\left(\delta_{\mathrm{H}-3}=3.667\right.$ p.p.m.; $\delta_{\mathrm{H}-4}=3.919$ p.p.m. $)$. The GlcNAc II' H-4 resonance is downfield-shifted in the bulk, and is not observable. Indeed, the C-4 substitution of GlcNAc with $\beta$-Gal is characterized by the occurrence of GlcNAc H-2, H3 and $\mathrm{H}-4$ signals at $\delta \approx 3.75$ p.p.m., as found for those observed for GlcNAc VI of C16, whereas a C-3 substitution should cause the downfield shift of the $\mathrm{H}-3$ resonance.

Compound B2 $(=\mathbf{C 1 9})$ contains three $\alpha$-Fuc, six $\alpha$-Gal, four $\beta$-Gal, two $\beta$-GlcNAc and one GalNAc-ol unit. Both Gal IV' and VIII H-1 resonances are upfield-shifted with respect to the $\mathrm{H}-1$ resonance of the $\alpha-\mathrm{Gal}$ of the 1,3 branch. The chemical shifts of the $\beta$-anomeric protons ( $\beta$-Gal and $\beta$-GlcNAc) are identical or similar to those observed in $\mathbf{C 1 7 - 3}$. From these observations, the structures of compounds C16, C17-3 and B2 were clearly established.

From the MALDI-TOF analysis (Table 1), C15-6 contains three Fuc, seven Gal, one GlcNAc and one GalNAc-ol. Its COSY spectrum (not shown), compared with $\mathbf{C 1 4}$, indicated the presence of one additional anomeric proton at $\delta=5.41$ p.p.m. and the downfield shift of Gal II H-2, H-3 and H-4 at $\delta=3.804$ p.p.m., 4.018 p.p.m. and 4.169 p.p.m. respectively. These NMR parameters have been shown to be characteristic of the sequence $\operatorname{Gal}(\beta 1-3)[\mathrm{Fuc}(\alpha 1-2)] \operatorname{Gal}(\beta 1-3)$ [28]. Moreover, the GalNAc-ol I H-6 and H- $6^{\prime}$ resonances at $\delta \approx 3.94$ p.p.m. and $\approx 3.68$ p.p.m. respectively are typical of the core type 2 . The structure of C156 was confirmed by methylation analysis, which showed, in particular, the di-substitution (at C-3 and C-6) of GalNAc-ol and the presence of 4,6-dimethylgalactose.

From the MALDI-TOF analysis (Table 1), compound B1 (= C18) contains two Fuc, ten Gal, two GlcNAc and one GalNAc-ol. The comparison of its NMR spectrum with that of compound B2 indicates that these two structures only differ in the number of fucose residues. To establish the position of the two remaining fucose units, this compound $\mathbf{B 1}$ was submitted to a periodic oxidation in order to separate the upper 1,6 branch from the lower 1,3 branch of the core type 2 . The sugar residue susceptible 
Table 2 'H-NMR chemical shifts of oligosaccharide-alditols D3, D5, C8-2, C10-2, C10-3 A and B, C11-4, and ${ }^{1} \mathrm{H} /{ }^{13} \mathrm{C}-\mathrm{NMR}$ chemical shifts of compound C12 nd: not determined; * , data from the HMQC experiment.

\begin{tabular}{|c|c|c|c|c|c|c|c|c|c|c|}
\hline Residues & Reporter group & D3 & $\mathrm{D} 5(=\mathrm{C} 5-2)$ & C8-2 & C10-2 & C10-3A & C10-3B & C11-4 & C12 & $\left({ }^{13} \mathrm{C}\right)$ \\
\hline \multirow[t]{9}{*}{ GalNAc-0| I } & $\mathrm{H}-1$ & nd & $\approx 3.82$ & 3.783 & 3.807 & $\approx 3.81$ & $\approx 3.81$ & $\approx 3.80$ & 3.802 & $(61.89)$ \\
\hline & $\mathrm{H}-1^{\prime}$ & & & & 3.745 & & & & & \\
\hline & $\mathrm{H}-2$ & $\approx 4.39$ & 4.390 & 4.405 & 4.387 & $\approx 4.39$ & $\approx 4.39$ & 4.389 & 4.387 & (52.86) \\
\hline & $\mathrm{H}-3$ & nd & 4.070 & 4.084 & 4.069 & 4.057 & 4.069 & 4.069 & 4.068 & (79.08) \\
\hline & $\mathrm{H}-4$ & nd & 3.552 & 3.497 & 3.549 & 3.462 & 3.543 & 3.556 & 3.552 & (70.66) \\
\hline & $\mathrm{H}-5$ & nd & 4.193 & 4.260 & 4.198 & 4.202 & 4.202 & 4.185 & 4.196 & (68.92) \\
\hline & $\mathrm{H}-6,6^{\prime}$ & nd & 3.936 & 3.924 & 3.927 & 3.93 & 3.93 & 3.935 & 3.936 & (72.42) \\
\hline & & & 3.687 & 3.702 & 3.687 & 3.69 & 3.69 & 3.688 & 3.684 & \\
\hline & NAc & 2.051 & 2.060 & 2.056 & 2.057 & 2.061 & 2.061 & 2.059 & 2.057 & $(23.46)$ \\
\hline \multirow[t]{6}{*}{ Gal II } & $\mathrm{H}-1$ & 4.543 & 4.534 & 4.569 & 4.534 & 4.530 & 4.530 & 4.530 & 4.531 & (104.64) \\
\hline & $\mathrm{H}-2$ & nd & 3.578 & 3.675 & 3.578 & 3.575 & 3.575 & 3.588 & 3.574 & (72.04) \\
\hline & $\mathrm{H}-3$ & nd & 3.770 & 3.873 & 3.771 & nd & nd & 3.773 & 3.775 & (73.60) \\
\hline & $\mathrm{H}-4$ & nd & 4.075 & 3.922 & 4.073 & nd & nd & 4.077 & 4.074 & (77.86) \\
\hline & $\mathrm{H}-5$ & nd & nd & nd & nd & nd & nd & nd & $3.793^{*}$ & (76.78) \\
\hline & $\mathrm{H}-6,6^{\prime}$ & nd & nd & nd & nd & nd & nd & nd & $3.905^{\star}$ & (61.65) \\
\hline \multirow[t]{6}{*}{ Gal III } & $\mathrm{H}-1$ & 4.985 & 4.988 & - & 4.991 & 4.944 & 4.993 & 4.984 & 4.99 & (101.35) \\
\hline & $\mathrm{H}-2$ & nd & $\approx 4.03$ & - & 4.000 & 3.831 & 4.019 & 4.013 & 4.003 & $(68.30)$ \\
\hline & $\mathrm{H}-3$ & nd & $\approx 4.03$ & - & 4.050 & nd & nd & 4.065 & 4.045 & (75.30) \\
\hline & $\mathrm{H}-4$ & nd & $\approx 4.03$ & - & 4.286 & nd & nd & 4.223 & 4.221 & $(66.97)$ \\
\hline & $\mathrm{H}-5$ & $\approx 4.39$ & 4.385 & - & 4.402 & $\approx 4.36$ & $\approx 4.36$ & nd & 4.393 & (72.04) \\
\hline & $\mathrm{H}-6,6^{\prime}$ & nd & $\approx 3.72$ & - & $\approx 3.72$ & $\approx 3.73$ & $\approx 3.73$ & $\approx 3.73$ & $\approx 3.73$ & $(61.87)$ \\
\hline \multirow[t]{6}{*}{ Gal IV } & $\mathrm{H}-1$ & 5.202 & 5.205 & - & 5.186 & - & 5.205 & 5.206 & 5.206 & (96.27) \\
\hline & $\mathrm{H}-2$ & nd & 3.962 & - & 3.888 & - & 3.966 & 3.967 & 3.959 & (75.92) \\
\hline & $\mathrm{H}-3$ & nd & 4.166 & - & 3.966 & - & $\approx 4.16$ & 4.167 & 4.166 & $(70.46)$ \\
\hline & $\mathrm{H}-4$ & nd & 4.047 & - & 4.026 & - & nd & 4.048 & 4.047 & (70.87) \\
\hline & $\mathrm{H}-5$ & nd & 4.227 & - & 4.194 & - & nd & 4.230 & 4.234 & (72.42) \\
\hline & $\mathrm{H}-6,6^{\prime}$ & nd & 3.76 & - & $\approx 3.74$ & - & nd & 3.755 & 3.76 & (62.66) \\
\hline \multirow[t]{8}{*}{ GlcNAc $\mathbf{I I}^{\prime}$} & $\mathrm{H}-1$ & - & 4.540 & 4.571 & 4.554 & 4.561 & 4.561 & $\approx 4.55$ & 4.550 & (102.90) \\
\hline & $\mathrm{H}-2$ & - & 3.719 & 3.755 & 3.753 & $\approx 3.76$ & $\approx 3.76$ & 3.76 & 3.757 & $(56.44)$ \\
\hline & $\mathrm{H}-3$ & - & 3.536 & 3.675 & nd & nd & nd & 3.677 & $3.696^{*}$ & $(74.00)$ \\
\hline & $\mathrm{H}-4$ & - & 3.433 & 3.696 & nd & nd & nd & nd & $3.701^{*}$ & $(80.23)$ \\
\hline & $\mathrm{H}-5$ & - & nd & 3.586 & 3.567 & nd & nd & 3.585 & $3.592^{\star}$ & (76.25) \\
\hline & $\mathrm{H}-6$ & - & 3.933 & 4.017 & nd & nd & nd & nd & nd & $(61.46)$ \\
\hline & $\mathrm{H}-6^{\prime}$ & & 3.715 & 3.855 & 3.850 & & & & & \\
\hline & NAc & - & 2.060 & 2.056 & 2.057 & 2.061 & 2.061 & 2.059 & 2.057 & $(23.46)$ \\
\hline \multirow[t]{6}{*}{ Gal III' } & $\mathrm{H}-1$ & - & - & 4.522 & 4.522 & 4.528 & 4.528 & 4.522 & 4.523 & (104.71) \\
\hline & $\mathrm{H}-2$ & - & - & 3.551 & 3.557 & $\approx 3.55$ & $\approx 3.55$ & 3.547 & 3.549 & (72.04) \\
\hline & H-3 & - & - & 3.755 & 3.748 & nd & nd & 3.751 & 3.761 & $(73.60)$ \\
\hline & $\mathrm{H}-4$ & - & - & 4.067 & 4.073 & nd & nd & 4.073 & 4.066 & (78.27) \\
\hline & $\mathrm{H}-5$ & - & - & nd & nd & nd & nd & nd & $3.793^{*}$ & (76.78) \\
\hline & $\mathrm{H}-6,6^{\prime}$ & - & - & nd & nd & nd & nd & nd & $3.905^{\star}$ & (61.65) \\
\hline \multirow[t]{6}{*}{ Gal IV' } & $\mathrm{H}-1$ & - & - & 4.990 & 4.991 & 4.985 & 4.944 & 4.991 & 4.99 & (101.35) \\
\hline & $\mathrm{H}-2$ & - & - & $\approx 4.01$ & 3.987 & 4.019 & 3.831 & 3.984 & 4.003 & $(68.30)$ \\
\hline & $\mathrm{H}-3$ & - & - & $\approx 4.01$ & 4.019 & nd & nd & 4.025 & 4.036 & (75.41) \\
\hline & $\mathrm{H}-4$ & - & - & 4.221 & 4.285 & nd & nd & 4.284 & 4.221 & (66.97) \\
\hline & $\mathrm{H}-5$ & - & - & 4.373 & 4.370 & $\approx 4.39$ & $\approx 4.39$ & nd & 4.364 & (72.04) \\
\hline & $\mathrm{H}-6,6^{\prime}$ & - & - & 3.714 & $\approx 3.72$ & $\approx 3.73$ & $\approx 3.73$ & $\approx 3.73$ & $\approx 3.73$ & $(61.87)$ \\
\hline \multirow[t]{6}{*}{ Gal $\mathbf{V}^{\prime}$} & $\mathrm{H}-1$ & - & - & 5.198 & 5.176 & 5.205 & - & 5.179 & 5.198 & (96.27) \\
\hline & $\mathrm{H}-2$ & - & - & 3.955 & 3.863 & 3.966 & - & 3.865 & 3.959 & (75.92) \\
\hline & $\mathrm{H}-3$ & - & - & 4.157 & 3.940 & $\approx 4.16$ & - & 3.94 & 4.157 & $(70.46)$ \\
\hline & $\mathrm{H}-4$ & - & - & 4.025 & 4.004 & nd & - & nd & 4.027 & (70.87) \\
\hline & $\mathrm{H}-5$ & - & - & 4.213 & 4.164 & nd & - & 4.166 & 4.215 & (72.42) \\
\hline & $\mathrm{H}-6,6^{\prime}$ & - & - & 3.744 & $\approx 3.73$ & nd & - & 3.742 & 3.75 & (62.66) \\
\hline \multirow[t]{6}{*}{ Fuc IV or II } & $\mathrm{H}-1$ & 5.226 & 5.226 & 5.222 & - & - & 5.226 & 5.226 & 5.223 & (101.66) \\
\hline & $\mathrm{H}-2$ & nd & 3.800 & 3.799 & - & - & 3.800 & 3.800 & 3.798 & (69.67) \\
\hline & $\mathrm{H}-3$ & nd & 3.893 & 3.927 & - & - & nd & 3.895 & 3.888 & (70.84) \\
\hline & $\mathrm{H}-4$ & nd & 3.818 & 3.823 & - & - & nd & nd & 3.826 & (73.02) \\
\hline & $\mathrm{H}-5$ & nd & 4.104 & 4.277 & - & - & 4.102 & 4.105 & 4.104 & $(68.49)$ \\
\hline & $\mathrm{CH}_{3}$ & 1.238 & 1.240 & 1.244 & - & - & 1.239 & 1.241 & 1.236 & (16.76) \\
\hline \multirow[t]{6}{*}{ Fuc $\mathbf{V}^{\prime}$} & $\mathrm{H}-1$ & - & - & 5.222 & - & 5.226 & - & - & 5.223 & (101.66) \\
\hline & $\mathrm{H}-2$ & - & - & 3.799 & - & 3.800 & - & - & 3.798 & (69.67) \\
\hline & $\mathrm{H}-3$ & - & - & 3.879 & - & nd & - & - & 3.888 & (70.84) \\
\hline & $\mathrm{H}-4$ & - & - & 3.823 & - & nd & - & - & 3.826 & (73.02) \\
\hline & $\mathrm{H}-5$ & - & - & 4.099 & - & 4.102 & - & - & 4.104 & $(68.49)$ \\
\hline & $\mathrm{CH}_{3}$ & - & - & 1.246 & - & 1.239 & - & - & 1.236 & (16.76) \\
\hline
\end{tabular}




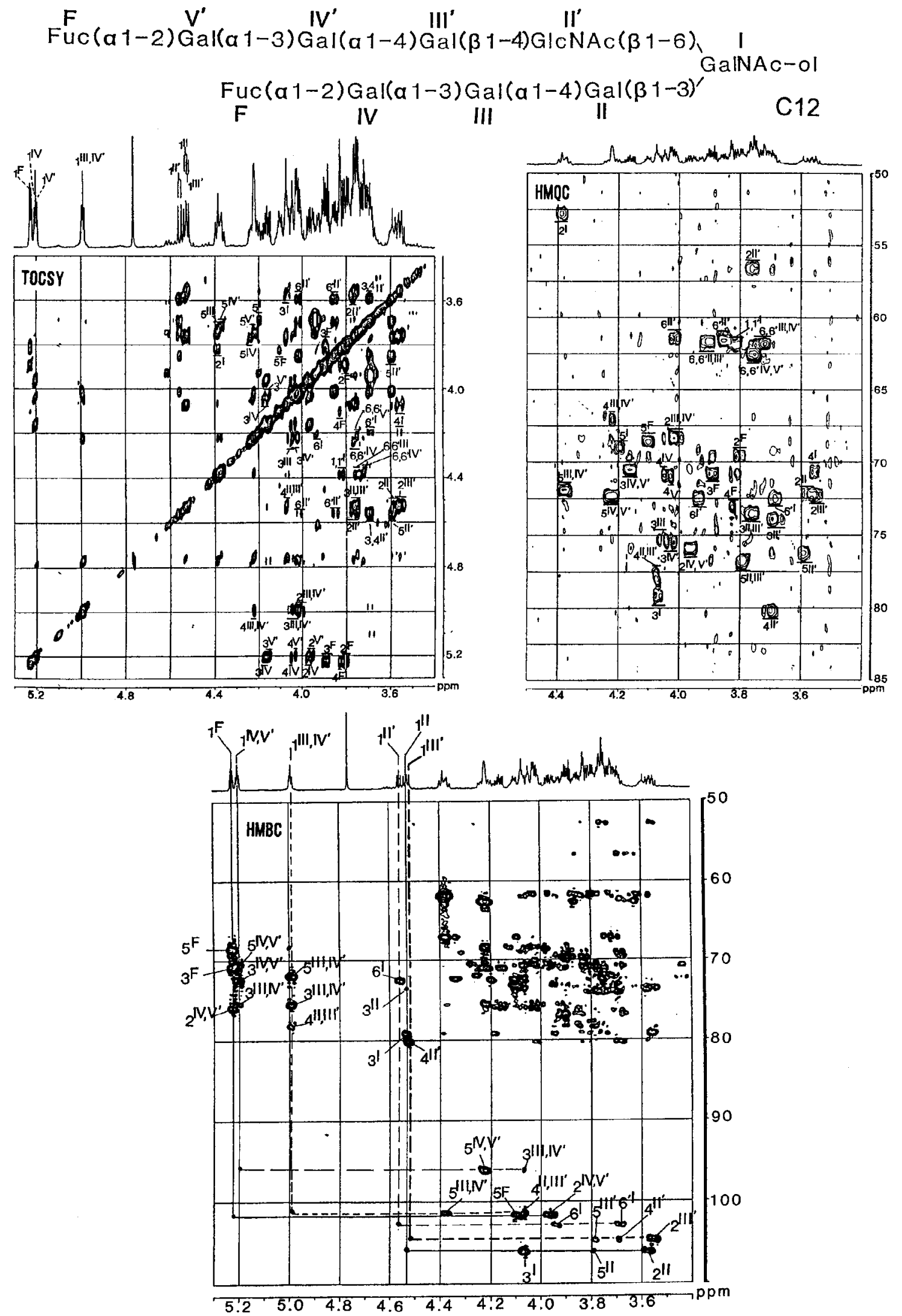

Figure 3 Homonuclear (TOCSY) and heteronuclear COSY spectra (HMQC and HMBC) of compound C12 
Table 3 'H-NMR chemical shifts of oligosaccharide alditols C14, C15-6, C16, C17-3, B1 and B2

nd, not determined; assignments denoted by asterisks may need to be interchanged.

\begin{tabular}{|c|c|c|c|c|c|c|c|}
\hline Residues & Reporter group & $\mathrm{C} 14$ & C15-6 & C16 & C17-3 & B1 (= C18) & B2 (= C19) \\
\hline \multirow[t]{9}{*}{ GalNAc-ol I } & $\mathrm{H}-1$ & $\approx 3.80$ & $\approx 3.79$ & 3.787 & 3.726 & nd & $\approx 3.75$ \\
\hline & $\mathrm{H}-1^{\prime}$ & $\approx 3.76$ & & & & & \\
\hline & $\mathrm{H}-2$ & 4.384 & 4.387 & 4.388 & 4.381 & 4.388 & 4.386 \\
\hline & $\mathrm{H}-3$ & 4.043 & 4.065 & 4.026 & 4.018 & nd & 4.023 \\
\hline & $\mathrm{H}-4$ & 3.528 & 3.552 & 3.489 & 3.481 & 3.492 & 3.492 \\
\hline & $\mathrm{H}-5$ & 4.153 & 4.201 & 4.239 & 4.230 & nd & 4.234 \\
\hline & $\mathrm{H}-6$, & $\approx 3.67$ & $\approx 3.94$ & 3.934 & 3.927 & nd & nd \\
\hline & $\mathrm{H}-6^{\prime}$ & & $\approx 3.68$ & 3.692 & 3.710 & & 3.701 \\
\hline & NAc & 2.060 & 2.060 & 2.049 & 2.044 & 2.050 & 2.050 \\
\hline \multirow[t]{4}{*}{ Gal II } & $\mathrm{H}-1$ & 4.538 & 4.584 & 4.528 & 4.519 & 4.524 & 4.523 \\
\hline & $\mathrm{H}-2$ & 3.734 & 3.804 & 3.732 & 3.729 & nd & 3.732 \\
\hline & $\mathrm{H}-3$ & 3.857 & 4.018 & 3.847 & 3.844 & nd & 3.850 \\
\hline & $\mathrm{H}-4$ & 4.125 & 4.169 & 4.124 & 4.117 & nd & 4.120 \\
\hline \multirow[t]{4}{*}{ Gal III } & $\mathrm{H}-1$ & 4.703 & 4.694 & 4.700 & 4.691 & 4.700 & 4.683 \\
\hline & $\mathrm{H}-2$ & 3.620 & 3.627 & 3.623 & 3.618 & nd & 3.623 \\
\hline & $\mathrm{H}-3$ & 3.759 & 3.740 & 3.760 & 3.755 & nd & 3.760 \\
\hline & $\mathrm{H}-4$ & 4.082 & 4.071 & 4.080 & 4.076 & nd & 4.082 \\
\hline \multirow[t]{6}{*}{ Gal IV } & $\mathrm{H}-1$ & 5.018 & 5.014 & 5.019 & 5.013 & 5.019 & 5.019 \\
\hline & $\mathrm{H}-2$ & 4.005 & $\approx 4.02$ & 4.010 & $\approx 4.01$ & nd & 4.006 \\
\hline & $\mathrm{H}-3$ & 4.053 & 4.032 & 4.069 & $\approx 4.02$ & nd & 4.055 \\
\hline & $\mathrm{H}-4$ & 4.227 & 4.219 & 4.239 & 4.222 & nd & 4.230 \\
\hline & $\mathrm{H}-5$ & 4.387 & 4.385 & 4.388 & 4.393 & 4.388 & nd \\
\hline & $\mathrm{H}-6,6^{\prime}$ & 3.715 & $\approx 3.72$ & 3.716 & 3.710 & nd & $\approx 3.72$ \\
\hline \multirow[t]{6}{*}{ Gal V } & $\mathrm{H}-1$ & 5.199 & 5.207 & 5.199 & 5.192 & 5.199 & 5.199 \\
\hline & $\mathrm{H}-2$ & 3.956 & 3.969 & 3.957 & 3.951 & nd & 3.957 \\
\hline & $\mathrm{H}-3$ & 4.158 & 4.167 & 4.158 & 4.156 & nd & 4.159 \\
\hline & $\mathrm{H}-4$ & 4.028 & 4.039 & 4.028 & 4.025 & nd & 4.029 \\
\hline & $\mathrm{H}-5$ & 4.377 & 4.221 & 4.214 & 4.210 & nd & 4.213 \\
\hline & $\mathrm{H}-6,6^{\prime}$ & $\approx 3.73$ & $\approx 3.75$ & 3.753 & 3.748 & nd & $\approx 3.75$ \\
\hline \multirow[t]{5}{*}{ GlcNAc VI } & $\mathrm{H}-1$ & 4.612 & - & 4.597 & 4.593 & 4.597 & 4.598 \\
\hline & $\mathrm{H}-2$ & 3.749 & - & $\approx 3.74$ & 3.736 & nd & 3.741 \\
\hline & $\mathrm{H}-3$ & 3.933 & - & $\approx 3.74$ & $\approx 3.74$ & nd & nd \\
\hline & $\mathrm{H}-4$ & 3.607 & - & $\approx 3.74$ & nd & nd & nd \\
\hline & NAc & 2.060 & - & 2.062 & $2.060^{\star}$ & 2.060 & 2.060 \\
\hline \multirow[t]{4}{*}{ Gal VII } & $\mathrm{H}-1$ & 4.524 & - & 4.52 & 4.519 & 4.524 & 4.523 \\
\hline & $\mathrm{H}-2$ & 3.549 & - & 3.55 & 3.545 & nd & 3.551 \\
\hline & $\mathrm{H}-3$ & 3.752 & - & 3.756 & 3.749 & nd & 3.755 \\
\hline & $\mathrm{H}-4$ & 4.064 & - & 4.067 & 4.062 & nd & 4.068 \\
\hline \multirow[t]{6}{*}{ Gal VIII } & $\mathrm{H}-1$ & 4.992 & - & 4.991 & 4.986 & 4.992 & 4.991 \\
\hline & $\mathrm{H}-2$ & 3.995 & - & $\approx 4.01$ & 3.991 & nd & 3.994 \\
\hline & $\mathrm{H}-3$ & 4.028 & - & $\approx 4.01$ & $\approx 4.02$ & nd & 4.030 \\
\hline & $\mathrm{H}-4$ & 4.219 & - & 4.208 & nd & nd & 4.220 \\
\hline & $\mathrm{H}-5$ & 4.371 & - & 4.371 & 4.380 & nd & 4.379 \\
\hline & $\mathrm{H}-6,6^{\prime}$ & 3.715 & - & nd & nd & nd & $\approx 3.72$ \\
\hline \multirow[t]{6}{*}{ Gal IX } & $\mathrm{H}-1$ & 5.199 & - & 5.199 & 5.192 & 5.199 & 5.199 \\
\hline & $\mathrm{H}-2$ & 3.956 & - & 3.957 & 3.951 & nd & 3.957 \\
\hline & $\mathrm{H}-3$ & 4.158 & - & 4.158 & 4.156 & nd & 4.159 \\
\hline & $\mathrm{H}-4$ & 4.028 & - & 4.028 & 4.022 & nd & 4.029 \\
\hline & $\mathrm{H}-5$ & 4.377 & - & 4.214 & 4.210 & nd & 4.213 \\
\hline & $H-6,6^{\prime}$ & $\approx 3.73$ & - & 3.753 & 3.748 & nd & $\approx 3.75$ \\
\hline \multirow[t]{6}{*}{ Fuc $\mathbf{V}$ and/or $\mathbf{V}^{\prime}$} & $\mathrm{H}-1$ & 5.226 & 5.224 & 5.226 & 5.220 & 5.224 & 5.226 \\
\hline & $\mathrm{H}-2$ & 3.800 & 3.797 & 3.799 & 3.795 & nd & 3.799 \\
\hline & $\mathrm{H}-3$ & 3.892 & 3.885 & 3.893 & 3.887 & nd & 3.892 \\
\hline & $\mathrm{H}-4$ & 3.827 & 3.823 & 3.826 & 3.825 & nd & 3.826 \\
\hline & $\mathrm{H}-5$ & 4.099 & 4.091 & 4.100 & 4.095 & nd & 4.100 \\
\hline & $\mathrm{CH}_{3}$ & 1.241 & 1.24 & 1.238 & 1.234 & 1.240 & 1.240 \\
\hline \multirow[t]{6}{*}{ Fuc IX } & $\mathrm{H}-1$ & 5.226 & - & 5.226 & 5.220 & 5.224 & 5.226 \\
\hline & $\mathrm{H}-2$ & 3.800 & - & 3.799 & 3.795 & nd & 3.799 \\
\hline & $\mathrm{H}-3$ & 3.892 & - & 3.893 & 3.887 & nd & 3.892 \\
\hline & $\mathrm{H}-4$ & 3.827 & - & 3.826 & 3.825 & nd & 3.826 \\
\hline & $\mathrm{H}-5$ & 4.099 & - & 4.100 & 4.095 & nd & 4.100 \\
\hline & $\mathrm{CH}_{3}$ & 1.241 & - & 1.238 & 1.234 & 1.240 & 1.240 \\
\hline Fuc II & $\mathrm{H}-1$ & - & 5.410 & - & - & - & - \\
\hline & $\mathrm{H}-2$ & - & 3.837 & - & - & - & - \\
\hline & $\mathrm{H}-3$ & - & 3.758 & - & - & - & - \\
\hline & $\mathrm{H}-4$ & - & nd & - & - & - & - \\
\hline & $\mathrm{H}-5$ & - & 4.218 & - & - & - & - \\
\hline & $\mathrm{CH}_{3}$ & - & 1.24 & - & - & - & - \\
\hline
\end{tabular}


Table 3 (contd.)

\begin{tabular}{|c|c|c|c|c|c|c|c|}
\hline Residues & Reporter group & C14 & C15-6 & C16 & C17-3 & B1 (= C18) & B2 $(=C 19)$ \\
\hline \multirow[t]{8}{*}{ GlcNAc II' } & $\mathrm{H}-1$ & - & 4.533 & 4.539 & 4.538 & 4.555 & 4.555 \\
\hline & $\mathrm{H}-2$ & - & 3.775 & 3.708 & 3.75 & nd & 3.750 \\
\hline & $\mathrm{H}-3$ & - & 3.653 & 3.532 & nd & nd & $\approx 3.68$ \\
\hline & $\mathrm{H}-4$ & - & 3.448 & 3.432 & nd & nd & nd \\
\hline & $\mathrm{H}-5$ & - & nd & 3.459 & nd & nd & nd \\
\hline & $\mathrm{H}-6$ & - & nd & 3.939 & nd & nd & nd \\
\hline & $H-6^{\prime}$ & & & 3.759 & & & \\
\hline & $N A C$ & - & 2.060 & 2.064 & $2.055^{\star}$ & 2.066 & 2.066 \\
\hline \multirow[t]{4}{*}{ Gal III' } & $\mathrm{H}-1$ & - & 4.529 & - & 4.465 & 4.524 & 4.523 \\
\hline & $\mathrm{H}-2$ & - & 3.574 & - & 3.536 & nd & 3.551 \\
\hline & $\mathrm{H}-3$ & - & 3.765 & - & 3.667 & nd & 3.755 \\
\hline & $\mathrm{H}-4$ & - & 4.071 & - & 3.919 & nd & 4.068 \\
\hline \multirow{6}{*}{ Gal IV' } & $\mathrm{H}-1$ & - & 4.983 & - & - & 4.992 & 4.991 \\
\hline & $\mathrm{H}-2$ & - & $\approx 4.02$ & - & - & nd & 3.994 \\
\hline & $\mathrm{H}-3$ & - & 4.016 & - & - & nd & 4.030 \\
\hline & $\mathrm{H}-4$ & - & 4.219 & - & - & nd & 4.220 \\
\hline & $\mathrm{H}-5$ & - & 4.362 & - & - & 4.370 & 4.379 \\
\hline & $H-6,6^{\prime}$ & - & $\approx 3.72$ & - & - & nd & $\approx 3.72$ \\
\hline \multirow[t]{6}{*}{ Gal $\mathbf{V}^{\prime}$} & $\mathrm{H}-1$ & - & 5.197 & - & - & 5.179 & 5.199 \\
\hline & $\mathrm{H}-2$ & - & 3.955 & - & - & nd & 3.957 \\
\hline & $\mathrm{H}-3$ & - & 4.146 & - & - & nd & 4.159 \\
\hline & $\mathrm{H}-4$ & - & 4.023 & - & - & nd & 4.029 \\
\hline & H-5 & - & 4.221 & - & - & nd & 4.213 \\
\hline & $\mathrm{H}-6,6^{\prime}$ & - & $\approx 3.75$ & - & - & nd & $\approx 3.75$ \\
\hline
\end{tabular}

to periodate oxidation in the moderate conditions used is the polyol (GalNAc-ol in this case), resulting in an opening of its $\mathrm{C} 4-\mathrm{C} 5$ bond. This selective periodic oxidation was followed by $\mathrm{NaBH}_{4}$ reduction, and analysis by MALDI-TOF spectrometry in the positive-ion mode. Treatment of compound $\mathbf{B} 1$ with the $\mathrm{NaIO}_{4} / \mathrm{NaBH}_{4}$ procedure resulted in four products characterized by their $[M+\mathrm{Na}]^{+}$pseudomolecular ions (Figure 5), which correlate with the predicted masses of the expected structures. The corresponding structures, derived from the upper branch (products $\mathrm{a}$ and $\mathrm{b}$ ) or from the lower part (products $\mathrm{c}$ and $\mathrm{d}$ ) of compound $\mathbf{B} 1$ are the following: product a, (at $m / z 775.2)=$ Gal-Gal-Gal-GlcNAc-ethanediol; product b (at $\mathrm{m} / z$ 921.3) $=$ Fuc-Gal-Gal-Gal-GlcNAc-ethanediol; and product $\mathrm{c}($ at $m / z$ $1670.7)$ is characterized by the loss of one of the two fucose units of product $\mathrm{d}$, which, at $m / z 1816.8$, is Fuc-Gal-Gal-Gal[FucGal-Gal-Gal-GlcNAc]Gal-TheNAc-ol (where TheNAc-ol represents 2-acetamido-2-deoxy-L-threitol).

These results indicate that $\mathbf{B} \mathbf{1}$ is a mixture of the compounds B1-A and B1-B, the structures of which are shown in Scheme 1. Moreover, the comparison between chemical shifts of $\mathrm{Gal}^{\prime} \mathrm{V}^{\prime}$ residues of both compounds $\mathbf{B} 1$ and $\mathbf{B} 2$ showed a shielding of $\Delta \delta$ $=-0.02$ p.p.m. of the $\mathrm{H}-1$ chemical shift in the case of compound B1. This is in favour of the unfucosylated form of the upper branch of compound B1. Therefore the compound B1-A seems to be the major compound of the mixture, as is also indicated by the MS results (major peaks a and d), whereas compound B1-B may possess two possible structures.

Compounds D1, C1(= D2), C5-3, C6, C10-4, C2, C5-1, C3, C7, C10-1, C5-4 and C8-1

The third series of oligosaccharide alditols (Scheme 2, Tables 4 and 5) is characterized by the presence of the two following inner-cores: $\operatorname{GlcNAc}(\beta 1-6)[\operatorname{Gal}(\beta 1-3)] \mathrm{GalNAc}-\mathrm{ol}$ and $\operatorname{Gal}(\beta 1-3)[\operatorname{GlcNAc}(\beta 1-6)] \operatorname{Gal}(\beta 1-3) \operatorname{GalNAc}-o l$. They are extended with different sequences or sugar units, such as the sequence $\operatorname{Fuc}(\alpha 1-3) \operatorname{GlcNAc}(\beta 1-6)$, the Lewis $\mathrm{X}$ determinant $\operatorname{Gal}(\beta 1-4)[\operatorname{Fuc}(\alpha 1-3)] \operatorname{GlcNAc}(\beta 1-6)$, the GalNAc unit $\beta 1,3-$ linked to the Gal II, III or III'

The monosubstitution (at C-3) or the di-substitution (at $\mathrm{C}-3$ and C-6) of GalNAc-ol was deduced from the characteristic chemical shifts of the GalNAc-ol H-6,6' protons. The sequence $\operatorname{Gal}(\beta 1-3)[\operatorname{GlcNAc}(\beta 1-6)] \operatorname{Gal}(\beta 1-3) \mathrm{GalNAc}-\mathrm{ol}$, which was established by methylation analysis, is characterized by the typical downfield-shifted resonances of Gal II H-2 $(\delta \approx 3.71$ p.p.m. $), \mathrm{H}-$ $3(\delta \approx 3.82$ p.p.m. $)$ and $\mathrm{H}-4(\delta \approx 4.16$ p.p.m. $)$ (Table 4$)$. The presence of the GlcNAc IV unit affects the H-5 and H-6,6' resonances of Gal II. The attachment of $\alpha$-Fuc to C-3 of GlcNAc was verified by methylation analysis of compound $\mathbf{C 1}$, which showed the presence of 4,6-dimethyl-GlcNAc. A comparison between the C5-3 and $\mathbf{C 1}$ spectra indicated that the C-3 fucosylation of GlcNAc II' is reflected by the downfield shift of the GlcNAc $\mathrm{H}-2$ resonance, from $\delta=3.696$ p.p.m. to $\delta=$ 3.843 p.p.m., and the $\mathrm{H}-3$ resonance, from $\delta=3.526$ p.p.m. to $\delta$ $=3.628$ p.p.m.. The C-3 fucosylation of GlcNAc II' (C1) or of GlcNAc IV (C5-3 and $\mathbf{C 1 0 - 4})$ gives rise to characteristic resonances of the Fuc H-1, observed at $\delta \approx 4.99$ and 4.97 p.p.m. respectively. Such a property is evident in the case of compound C6, which possesses these two fucose units (Table 4).

The Lewis $\mathrm{X}$ determinant is present in compounds C5-1 and C10-4. In the case of C5-1, the attachment of GlcNAc IV to C6 of Gal II was deduced from the characteristic downfield shift of the Gal II H-6,6' resonances. Moreover, the core structure Gal( $\beta 1-3)$ GalNAc-ol was deduced from the GalNAc-ol H-6,6' signals at $\delta \approx 3.65$ p.p.m. The structural reporter-group signals of the fucose unit present in the Lewis $\mathrm{X}$ sequences match with the data from the literature [25]. The comparison of the NMR spectra of $\mathbf{C 6}$ and $\mathbf{C 1 0 - 4}$ clearly indicates that both contain the sequence $\operatorname{Fuc}(\alpha 1-3) \operatorname{GlcNAc}(\beta 1-6)[\operatorname{Gal}(\beta 1-3)] \operatorname{Gal}(\beta 1-3)$ GalNAc-ol. Consequently, the Lewis X determinant, in compound $\mathbf{C 1 0 - 4}$, is attached to C-6 of GalNAc-ol. 

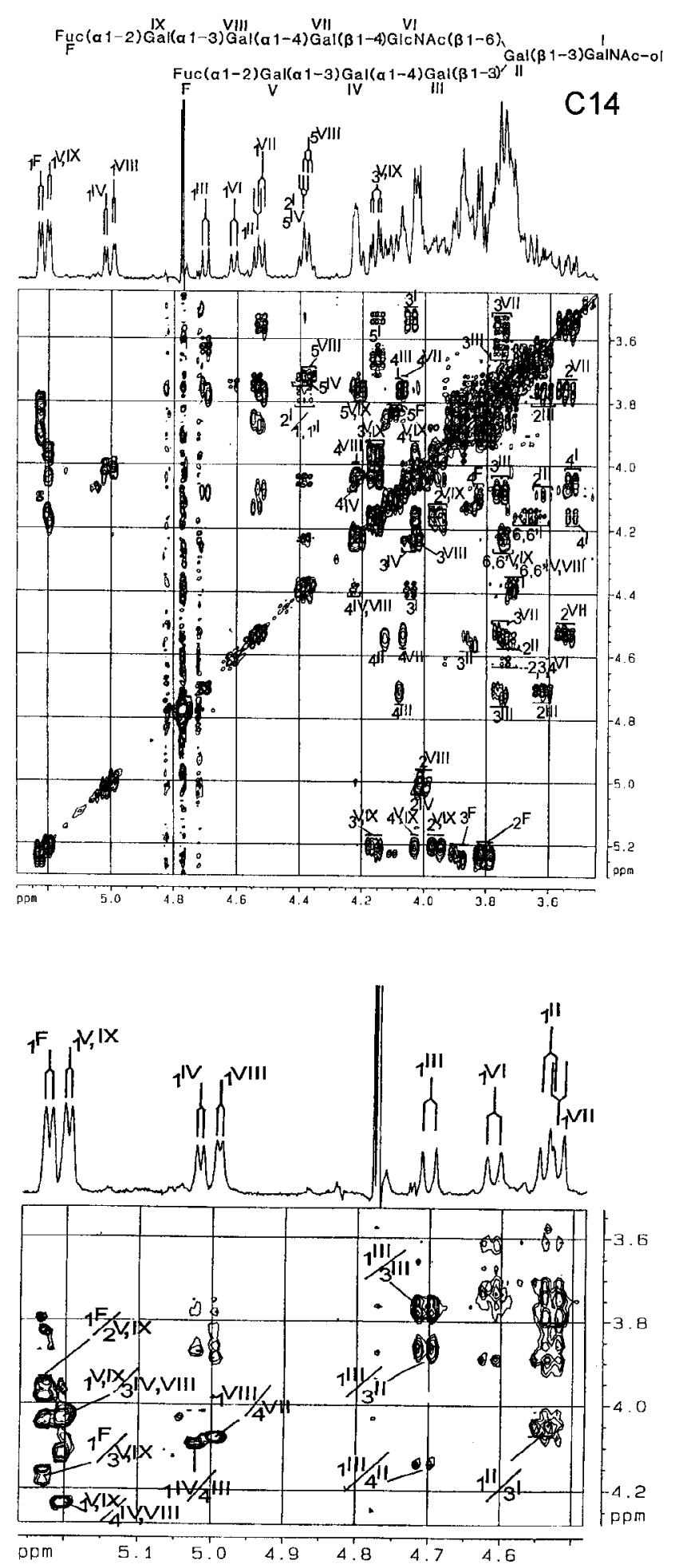

Figure 4 Double relayed COSY spectrum (top panel), and extension (5.26 to 4.48 p.p.m. in F2 and 4.27 to 3.53 p.p.m. in F1) of the ROESY spectrum (bottom panel) of compound C14

The presence of $\beta$-GalNAc in compounds C3, C7, C10-1, C54 and C8-1 is deduced from the set of its vicinal coupling constants measured on the COSY spectra (results not shown). The $\mathrm{H}-4$ resonance, found at $\delta=3.93$ p.p.m., is clearly observed in the COSY spectrum of $\mathbf{C 1 0 - 1}$. The chemical shifts of the H-1

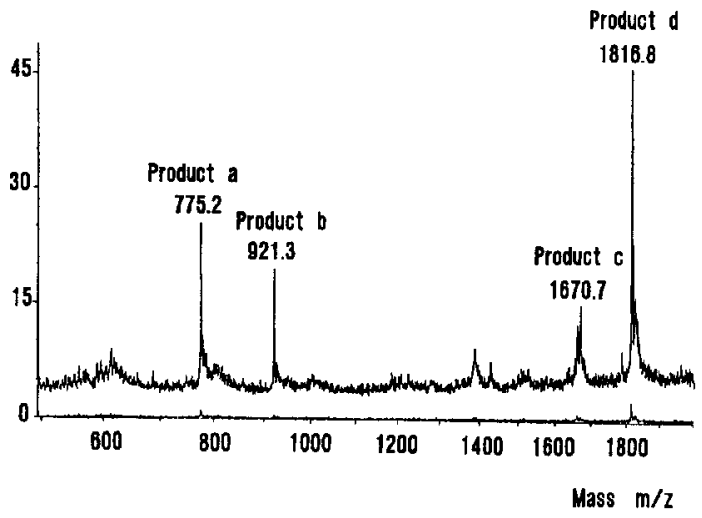

Figure 5 MALDI-TOF analysis of compound B1 after mild periodic oxidation and reduction

Analysis was performed in the positive mode (pseudomolecular ions; $[\mathrm{M}+\mathrm{Na}]^{+}$)

to $\mathrm{H}-4$ resonances of $\beta$-GalNAc are typical of a terminal nonreducing unit, whereas the downfield shifts observed for the $\mathrm{H}$ 3 and $\mathrm{H}-4$ resonances of Gal II (C3 and C10-1), Gal III (C5-4 and C8-1) and Gal III' (C7 and C10-1) can be attributed to a C-3 or a C-4 substitution of $\beta$-Gal (Table 5). The 1,3 linkage was proved conclusively by methylation analysis, which clearly showed the presence of 2,4,6-trimethylgalactose.

\section{DISCUSSION}

In the present study, the carbohydrate chains from $R$. clamitans oviducal mucins were released by reductive $\beta$-elimination. Neutral oligosaccharide alditols, which constitute the main fraction of the isolated oligosaccharide alditols, were separated from acidic oligosaccharide alditols and fractionated by a sequence of chromatographic techniques. The structures of 27 of them, ranging in size from a trisaccharide to a hexadecasaccharide, were determined using NMR spectroscopy, MALDI-TOF MS and methylation analyses.

The remarkable species-specific structural diversity, which has been observed in carbohydrate chains of other amphibian-egg jellies, was verified for $R$. clamitans, as shown in Schemes 1 and 2. Indeed, the structures presented are novel and characteristic of $R$. clamitans, even if some parts of their sequences have been observed already in other amphibians.

The structural features of these oligosaccharide alditols can be summarized as follows. They possess type- 1 or -2 cores, i.e. $\operatorname{Gal}(\beta 1-3)$ GalNAc-ol and $\operatorname{GlcNAc}(\beta 1-6)[\operatorname{Gal}(\beta 1-3)] \operatorname{GalNAc-}$ ol respectively. In these O-glycans, the $\operatorname{Gal}(\beta 1-3)$ GalNAc-ol core can be extended at the $\mathrm{Gal}$ residue with a $\mathrm{Gal}(\beta 1-3)$ residue. The sequence $\operatorname{Gal}(\beta 1-3) \mathrm{Gal}(\beta 1-3) \mathrm{GalNAc-ol}$ is also present in the oviducal mucins of other amphibian species: $B$. bufo $[15,26]$, R. temporaria [14], R. arvalis [27], R. ridibunda [29] and Xenopus laevis [13]. As reported for some of these species previously $[26,27]$, a GlcNAc unit $\beta-1,6$ linked to Gal II may be observed in the case of $R$. clamitans.

Several carbohydrate chains of $R$. clamitans (first and second series; see Scheme 1) contain the blood-group $\mathrm{P}_{1}$ determinant $\operatorname{Gal}(\alpha 1-4) \operatorname{Gal}(\beta 1-4) G l c N A c \beta$-. This sequence has been found previously in Ambystoma mexicanum [30] in a fucosylated form $\{-\mathrm{Fuc}(\alpha 1-2)[\mathrm{Gal}(\alpha 1-4)] \mathrm{Gal}(\beta 1-4) \mathrm{GlcNAc}-\}$, which could be considered as the hybrid $\mathrm{P}_{1} / \mathrm{H}$ blood group determinant. However, in $R$. clamitans, the $\mathrm{P}_{1}$ determinant is extended at the $\alpha$-Gal residue with a $\operatorname{Gal}(\alpha 1-3)$ residue or with a $\operatorname{Fuc}(\alpha 1-2) \operatorname{Gal}(\alpha 1-3)$ 
Table 4 ' ${ }^{1} \mathrm{H}-\mathrm{NMR}$ chemical shifts of oligosaccharide-alditols D1, C1, C5-3, C6, C10-4, C2 and C5-1

nd, not determined.

\begin{tabular}{|c|c|c|c|c|c|c|c|c|}
\hline Residues & Reporter group & D1 & $\mathrm{C} 1$ (= D2) & C5-3 & C6 & C10-4 & C2 & C5-1 \\
\hline \multirow[t]{9}{*}{ GalNAc-ol I } & $\mathrm{H}-1$ & nd & 3.78 & 3.784 & 3.788 & 3.783 & nd & 3.574 \\
\hline & $\mathrm{H}-1^{\prime}$ & & 3.744 & 3.725 & 3.726 & 3.722 & & nd \\
\hline & $\mathrm{H}-2$ & 4.395 & 4.393 & 4.385 & 4.386 & 4.384 & 4.384 & 4.382 \\
\hline & $\mathrm{H}-3$ & 4.060 & 4.062 & 4.024 & 4.022 & 4.022 & 4.044 & 4.043 \\
\hline & $\mathrm{H}-4$ & 3.468 & 3.456 & 3.491 & 3.481 & 3.474 & 3.528 & 3.523 \\
\hline & $\mathrm{H}-5$ & 4.279 & 4.277 & 4.226 & 4.227 & 4.220 & 4.154 & 4.155 \\
\hline & $H-6,6^{\prime}$ & 3.931 & 3.931 & 3.934 & 3.936 & 3.930 & nd & 3.65 \\
\hline & & nd & 3.679 & 3.694 & 3.691 & 3.686 & & \\
\hline & NAC & 2.066 & 2.050 & 2.058 & 2.043 & 2.046 & 2.046 & 2.044 \\
\hline \multirow[t]{7}{*}{ Gal II } & $\mathrm{H}-1$ & 4.464 & 4.463 & 4.532 & 4.530 & 4.529 & 4.612 & 4.534 \\
\hline & $\mathrm{H}-2$ & 3.542 & 3.559 & 3.722 & 3.712 & 3.713 & nd & 3.715 \\
\hline & $\mathrm{H}-3$ & nd & nd & 3.825 & 3.824 & 3.824 & nd & 3.829 \\
\hline & $\mathrm{H}-4$ & 3.900 & 3.900 & 4.166 & 4.168 & 4.166 & 4.168 & 4.165 \\
\hline & $\mathrm{H}-5$ & nd & nd & 3.879 & 3.883 & nd & nd & nd \\
\hline & $\mathrm{H}-6$ & nd & nd & 3.975 & 3.958 & nd & nd & 3.956 \\
\hline & $H-6^{\prime}$ & & & 3.879 & 3.883 & & & 3.858 \\
\hline \multirow[t]{4}{*}{ Gal III } & $\mathrm{H}-1$ & - & - & 4.610 & 4.610 & 4.607 & 4.603 & 4.609 \\
\hline & $\mathrm{H}-2$ & - & - & 3.606 & 3.608 & 3.606 & nd & 3.603 \\
\hline & $\mathrm{H}-3$ & - & - & nd & 3.671 & 3.657 & nd & 3.688 \\
\hline & $\mathrm{H}-4$ & - & - & nd & 3.927 & 3.924 & 3.925 & 3.924 \\
\hline \multirow{4}{*}{ Gal V } & $\mathrm{H}-1$ & - & - & - & - & - & - & 4.448 \\
\hline & $\mathrm{H}-2$ & - & - & - & - & - & - & 3.494 \\
\hline & $\mathrm{H}-3$ & - & - & - & - & - & - & 3.651 \\
\hline & $\mathrm{H}-4$ & - & - & - & - & - & - & 3.896 \\
\hline \multirow[t]{8}{*}{ GlcNAc IV } & $\mathrm{H}-1$ & - & - & 4.586 & 4.587 & 4.587 & 4.542 & 4.609 \\
\hline & $\mathrm{H}-2$ & - & - & 3.824 & 3.824 & 3.823 & nd & 3.909 \\
\hline & $\mathrm{H}-3$ & - & - & 3.658 & 3.668 & 3.661 & nd & 3.909 \\
\hline & $\mathrm{H}-4$ & - & - & 3.530 & 3.526 & 2.522 & nd & $\approx 3.58$ \\
\hline & $\mathrm{H}-5$ & - & - & nd & nd & nd & nd & $\approx 3.58$ \\
\hline & $\mathrm{H}-6$ & - & - & 3.952 & nd & nd & nd & 4.006 \\
\hline & $H-6^{\prime}$ & & & 3.764 & & & & 3.858 \\
\hline & NAc & - & - & 2.033 & 2.033 & 2.031 & 2.042 & 2.044 \\
\hline \multirow[t]{6}{*}{ Fuc IV } & $\mathrm{H}-1$ & - & - & 4.974 & 4.975 & 4.973 & 4.980 & 5.098 \\
\hline & $\mathrm{H}-2$ & - & - & 3.690 & 3.690 & 3.690 & nd & 3.684 \\
\hline & $\mathrm{H}-3$ & - & - & nd & 3.827 & 3.824 & nd & 3.898 \\
\hline & $\mathrm{H}-4$ & - & - & nd & 3.795 & 3.796 & nd & 3.789 \\
\hline & $\mathrm{H}-5$ & - & - & 4.321 & 4.324 & 4.320 & 4.324 & 4.830 \\
\hline & $\mathrm{CH}_{3}$ & - & - & 1.156 & 1.158 & 1.155 & 1.157 & 1.171 \\
\hline \multirow[t]{6}{*}{ Fuc II' } & $\mathrm{H}-1$ & - & 4.987 & - & 4.993 & 5.112 & - & - \\
\hline & $\mathrm{H}-2$ & - & 3.691 & - & 3.690 & 3.684 & - & - \\
\hline & $\mathrm{H}-3$ & - & 3.994 & - & 3.827 & 3.902 & - & - \\
\hline & $\mathrm{H}-4$ & - & nd & - & 3.795 & 3.790 & - & - \\
\hline & $\mathrm{H}-5$ & - & 4.326 & - & 4.324 & 4.881 & - & - \\
\hline & $\mathrm{CH}_{3}$ & - & 1.158 & - & 1.158 & 1.174 & - & - \\
\hline \multirow[t]{8}{*}{ GlcNAc II' } & $\mathrm{H}-1$ & 4.539 & 4.546 & 4.536 & 4.547 & 4.560 & - & - \\
\hline & $\mathrm{H}-2$ & nd & 3.843 & 3.696 & 3.837 & 3.920 & - & - \\
\hline & $\mathrm{H}-3$ & nd & 3.628 & 3.526 & 3.635 & 3.822 & - & - \\
\hline & $\mathrm{H}-4$ & 3.452 & 3.516 & 3.431 & 3.514 & $\approx 3.88$ & - & - \\
\hline & $\mathrm{H}-5$ & nd & 3.482 & 3.470 & 3.489 & 3.596 & - & - \\
\hline & $\mathrm{H}-6$ & nd & 3.942 & 3.924 & 3.927 & 4.011 & - & - \\
\hline & $H-6^{\prime}$ & & 3.749 & 3.734 & 3.657 & 3.856 & & \\
\hline & NAC & 2.066 & 2.066 & 2.063 & 2.064 & 2.064 & - & - \\
\hline \multirow[t]{4}{*}{ Gal III' } & $\mathrm{H}-1$ & - & - & - & - & 4.448 & - & - \\
\hline & $\mathrm{H}-2$ & - & - & - & - & 3.493 & - & - \\
\hline & $\mathrm{H}-3$ & - & - & - & - & 3.653 & - & - \\
\hline & $\mathrm{H}-4$ & - & - & - & - & 3.898 & - & - \\
\hline
\end{tabular}

sequence. The occurrence of a peripheral additional sugar or sequence linked to a blood-group determinant has been already observed for several amphibian species, i.e. B. bufo $[15,26]$ and $X$. laevis [31].

Another characteristic feature of the $R$. clamitans mucin consists of the presence of the peripheral trisaccharide $\operatorname{Fuc}(\alpha 1-2) \operatorname{Gal}(\alpha 1-3) \operatorname{Gal}(\alpha 1-4)$, directly attached in the first series of compounds (D3 to $\mathbf{C 1 2}$ ) to the $\beta$-Gal II unit of the type-1 or
-2 cores, and/or to the $\beta$-Gal III' unit of the type- 2 core. The second series of compounds (C14 to B2), characterized by the presence of the backbone $\operatorname{Gal}(\beta 1-3) \operatorname{Gal}(\beta 1-3)$, also possesses this peripheral trisaccharide, which can be attached to the $\beta$-Gal III and the $\beta$-Gal VII units of the type- 1 or -2 cores, and/or to the $\beta$-Gal III' unit of the type- 2 core. This new structural characteristic is well represented in the compound B2, which comprises 16 monosaccharidic units, and particularly this tri- 
Table 5 ' ${ }^{1} \mathrm{H}$-NMR chemical shifts of oligosaccharide-alditols C3, C7, C10-1, C5-4 and C8-1

nd, not determined; the asterisks denote that assignments may have to be interchanged.

\begin{tabular}{|c|c|c|c|c|c|c|}
\hline Residues & Reporter group & C3 & C7 & C10-1 & C5-4 & C8-1 \\
\hline \multirow[t]{9}{*}{ GalNAc-0l I } & $\mathrm{H}-1$ & 3.753 & $\approx 3.75$ & 3.755 & 3.787 & 3.768 \\
\hline & $\mathrm{H}-1^{\prime}$ & nd & & & 3.726 & 3.720 \\
\hline & $\mathrm{H}-2$ & 4.399 & 4.394 & 4.398 & 4.383 & 4.387 \\
\hline & $\mathrm{H}-3$ & 4.046 & 4.059 & 4.045 & 4.043 & 4.021 \\
\hline & $\mathrm{H}-4$ & 3.441 & 3.448 & 3.433 & 3.527 & 3.487 \\
\hline & $\mathrm{H}-5$ & 4.265 & 4.269 & 4.250 & 4.150 & 4.226 \\
\hline & $\mathrm{H}-6$ & 3.925 & 3.925 & 3.917 & 3.650 & 3.932 \\
\hline & $\mathrm{H}-6^{\prime}$ & 3.670 & 3.673 & 3.669 & & 3.690 \\
\hline & NAC & 2.045 & 2.054 & 2.049 & 2.045 & 2.055 \\
\hline \multirow[t]{7}{*}{ Gal II } & $\mathrm{H}-1$ & 4.449 & 4.461 & 4.447 & 4.731 & 4.532 \\
\hline & $\mathrm{H}-2$ & 3.591 & 3.559 & 3.589 & 3.714 & 3.706 \\
\hline & $\mathrm{H}-3$ & 3.729 & 3.673 & 3.732 & 3.815 & 3.807 \\
\hline & $\mathrm{H}-4$ & 4.131 & 3.898 & 4.132 & 4.164 & 4.165 \\
\hline & $\mathrm{H}-5$ & nd & nd & nd & 3.871 & 3.872 \\
\hline & $\mathrm{H}-6$ & nd & nd & nd & 3.965 & 3.973 \\
\hline & $\mathrm{H}-6^{\prime}$ & & & & 3.892 & 3.889 \\
\hline \multirow[t]{4}{*}{ Gal III } & $\mathrm{H}-1$ & - & - & - & 4.540 & 4.590 \\
\hline & $\mathrm{H}-2$ & - & - & - & 3.641 & 3.641 \\
\hline & $\mathrm{H}-3$ & - & - & - & 3.741 & 3.739 \\
\hline & $\mathrm{H}-4$ & - & - & - & 4.143 & 4.148 \\
\hline \multirow[t]{5}{*}{ GalNAc III or IV } & $\mathrm{H}-1$ & 4.594 & - & 4.589 & 4.628 & 4.623 \\
\hline & $\mathrm{H}-2$ & 3.945 & - & 3.944 & 3.936 & 3.933 \\
\hline & $\mathrm{H}-3$ & 3.750 & - & 3.749 & 3.749 & 3.752 \\
\hline & $\mathrm{H}-4$ & 3.940 & - & 3.930 & 3.933 & nd \\
\hline & $\mathrm{Nac}$ & 2.041 & - & 2.039 & $2.039^{*}$ & $2.028^{*}$ \\
\hline \multirow[t]{8}{*}{ GlcNAc V } & $\mathrm{H}-1$ & - & - & - & 4.599 & 4.580 \\
\hline & $\mathrm{H}-2$ & - & - & - & 3.834 & 3.818 \\
\hline & $\mathrm{H}-3$ & - & - & - & 3.681 & 3.655 \\
\hline & $\mathrm{H}-4$ & - & - & - & 3.525 & 3.523 \\
\hline & $\mathrm{H}-5$ & - & - & - & 3.488 & 3.449 \\
\hline & $\mathrm{H}-6$ & - & - & - & 3.957 & 3.947 \\
\hline & $\mathrm{H}-6^{\prime}$ & & & & 3.754 & 3.738 \\
\hline & NAC & - & - & - & $2.035^{\star}$ & $2.032^{*}$ \\
\hline \multirow[t]{6}{*}{ Fuc $\mathbf{V}$} & $\mathrm{H}-1$ & - & - & - & 4.978 & 4.968 \\
\hline & $\mathrm{H}-2$ & - & - & - & 3.689 & 3.685 \\
\hline & $\mathrm{H}-3$ & - & - & - & 3.825 & 3.824 \\
\hline & $\mathrm{H}-4$ & - & - & - & 3.796 & 3.793 \\
\hline & $\mathrm{H}-5$ & - & - & - & 4.323 & 4.317 \\
\hline & $\mathrm{CH}_{3}$ & - & - & - & 1.155 & 1.152 \\
\hline \multirow[t]{6}{*}{ Fuc $\mathbf{I I}^{\prime}$} & $\mathrm{H}-1$ & 4.987 & 5.097 & 5.097 & - & - \\
\hline & $\mathrm{H}-2$ & 3.690 & 3.963 & 3.681 & - & - \\
\hline & $\mathrm{H}-3$ & 3.826 & 3.888 & 3.886 & - & - \\
\hline & $\mathrm{H}-4$ & 3.800 & 3.776 & 3.775 & - & - \\
\hline & $\mathrm{H}-5$ & 4.324 & 4.819 & 4.818 & - & - \\
\hline & $\mathrm{CH}_{3}$ & 1.157 & 1.154 & 1.153 & - & - \\
\hline \multirow[t]{8}{*}{ GlcNAc II' } & $\mathrm{H}-1^{3}$ & 4.540 & 4.559 & 4.553 & - & 4.532 \\
\hline & $\mathrm{H}-2$ & 3.837 & $\approx 3.92$ & 3.915 & - & 3.706 \\
\hline & H-3 & 3.619 & 3.832 & 3.822 & - & 3.525 \\
\hline & $\mathrm{H}-4$ & 3.515 & $\approx 3.92$ & nd & - & 3.430 \\
\hline & $\mathrm{H}-5$ & 3.489 & 3.594 & nd & - & 3.500 \\
\hline & $\mathrm{H}-6$ & 3.937 & 4.003 & nd & - & 3.936 \\
\hline & $\mathrm{H}-6^{\prime}$ & 3.748 & 3.843 & & & 3.751 \\
\hline & NAc & 2.066 & 2.068 & 2.067 & - & 2.060 \\
\hline \multirow{6}{*}{ Gal III' } & $\mathrm{H}-1$ & - & 4.432 & 4.429 & - & - \\
\hline & $\mathrm{H}-2$ & - & 3.516 & 3.509 & - & - \\
\hline & $\mathrm{H}-3$ & - & 3.720 & 3.720 & - & - \\
\hline & $\mathrm{H}-4$ & - & 4.103 & 4.103 & - & - \\
\hline & $\mathrm{H}-5$ & - & nd & nd & - & - \\
\hline & $\mathrm{H}-6,6^{\prime}$ & - & nd & nd & - & - \\
\hline \multirow[t]{5}{*}{ GalNAc IV' } & $\mathrm{H}-1$ & - & 4.612 & 4.612 & - & - \\
\hline & $\mathrm{H}-2$ & - & 3.930 & 3.932 & - & - \\
\hline & $\mathrm{H}-3$ & - & 3.741 & 3.737 & - & - \\
\hline & $\mathrm{H}-4$ & - & 3.934 & 3.930 & - & - \\
\hline & NAc & - & 2.032 & 2.030 & - & - \\
\hline
\end{tabular}


saccharidic sequence repeated in a tri-antennary structure. However, different intermediates of the biosynthesis of the complete glycan were also isolated. Thus a novel type of chain termination, constituted by the sequence $\operatorname{Fuc}(\alpha 1-2) \mathrm{Gal}(\alpha 1-3)$ $\operatorname{Gal}-(\alpha 1-4) \operatorname{Gal}(\beta 1-3 / 4)$, is shown here.

The structural features of the third series of compounds (Scheme 2) are the sequence $\operatorname{Fuc}(\alpha 1-3) \operatorname{GlcNAc}(\beta 1-6)$ and the Lewis $\mathrm{X}\left(\mathrm{Le}^{\mathrm{x}}\right)$ determinant $\operatorname{Gal}(\beta 1-4)[\operatorname{Fuc}(\alpha 1-3)] \operatorname{GlcNAc}(\beta 1-6)$. $\mathrm{O}$-glycans containing $\mathrm{Le}^{\mathrm{x}}$ determinants have been already found in the oviducal mucins of some other amphibian species, such as Pleurodeles waltl [32] or A. tigrinum [33] and, more recently, these two sequences were observed in $X$. laevis [31]. However, in the case of $R$. clamitans, the unfucosylated $\operatorname{Gal}(\beta 1-4) \operatorname{GlcNAc}(\beta 1-6)$ sequence is not observed. Therefore it appears that the synthesis of $\mathrm{Le}^{\mathrm{x}}$ by $R$. clamitans may be achieved in a different manner to that observed in the human system [34], with a fucosylation of the GlcNAc unit before its galactosylation. Biosynthetic pathways that are distinct from those of the human system have been described previously for the biosynthesis of Lewis determinants by Helicobacter pylori [35].

Another characteristic of this same series of compounds is the presence of a GalNAc unit $\beta 1,3$-linked to the $\beta$-Gal II, III or III' residues. Such a linkage has been rarely observed until now in amphibian species. Moreover, it is noteworthy that this GalNAc unit can be attached to the $\mathrm{Le}^{\mathrm{x}}$ determinant (compounds $\mathbf{C} 7$ and C10-1).

Since the present study was performed on the neutral pool of oligosaccharide alditols, the next study on the acidic compounds will contribute to the characterization of this species. However, these results already confirm our previous conclusions concerning the species-specificity of the O-linked glycans released from the amphibian-egg jelly coats. Among all the characterized neutral compounds released from the mucin of $R$. clamitans, most of them have novel structures, even if they include some known structural patterns, such as $\mathrm{Le}^{\mathrm{x}}$ or $\mathrm{P}_{1}$ determinants. These glycans can be considered as phenotypic markers of the species. Such a species specificity has been observed for all amphibian species studied up to now [12-19,26-29]. These structural analyses also suggest the existence of new glycosylation pathways and, consequently, new glycosyltransferase activities.

From a general point of view, it is noteworthy that the presence of galabiose (Gal $\alpha 1-4 \mathrm{Gal})$ in animal $\mathrm{N}$ - or O-glycans was rarely observed, while this sequence is normally found in terminal and internal positions of mammalian glycolipids bearing the $\mathrm{P}_{1}$ or $\mathrm{P}^{\mathrm{k}}$ determinants, as described in [36]. Moreover, the glycolipids containing galabiose are known to be targets on host cells for infection by some pathogenic microbes, whereas galabiose-containing glycoproteins were found only when the mammals were infected by tapeworm Echinococcus granulosus [36]. Therefore the diversity in glycan structures may reflect the diversity of glycosyltransferases involved in their biosynthesis. From a biological point of view, the species specificity and diversity of glycans could be related to the host-parasite interaction that led to the selection of glycosyltransferase activities during evolution [20].

This research was supported by the Centre National de la Recherche Scientifique (Unité Mixte de Recherche 8576, Glycobiologie Structurale et Fonctionnelle) and by the Ministère de I'Enseignement Supérieur et de la Recherche. We thank G. Ricart and $\mathrm{Y}$. Leroy for MS analyses.

\section{REFERENCES}

1 Freeman, S. B. (1968) A study of the jelly envelopes surrounding the egg of the amphibian Xenopus laevis. Biol. Bull. 135, 501-513
2 Schmell, E. D., Gulyas, B. J. and Hedrick, J. L. (1983) Egg surface changes during fertilization and the molecular mechanism of the block to polyspermy. In Mechanism and Control of Animal Fertilization (Hartmann, J. F., ed.), pp. 365-413, Academic Press, New York, NY

3 Wolf, D. P. and Hedrick, J. L. (1971) A molecular approach to fertilization. Development of a bioassay for sperm capacitation. Dev. Biol. 25, 360-376

4 Raisman, J. S. and Cabada, M. O. (1977) Acrosomic reaction and proteolytic activity in the spermatozoa of an anuran amphibian, Leptodactylus chaquensis. Dev. Growth Differ. 19, 227-232

5 Hedrick, J. L. and Nishihara, T. (1991) Structure and function of the extracellular matrix of anuran eggs. J. Electron Microsc. Tech. 17, 319-335

6 Jego, P., Joly, J. and Boisseau, C. (1980) Amphibian jelly envelopes, proteins secreted by the oviduct and surrounding the eggs: their role in fertilization. Reprod. Nutr. Dev. 20, 557-567

7 Shimoda, Y., Kitajima, K., Inoue, S. and Inoue, Y. (1994) Isolation, structural determination, and calcium-binding properties of the major glycoprotein present in Bufo japonicus japonicus egg jelly. Eur. J. Biochem. 223, 223-231

8 Shaver, J. R., Barch, S. H. and Umpierre, C. C. (1970) Interspecific relationships of oviducal materials as related to fertilization in amphibia. J. Embryol. Exp. Morphol. 24, 209-225

9 Ishihara, K., Hosono, J., Kanatani, H. and Katagiri, C. (1984) Toad egg-jelly as a source of divalent cations essential for fertilization. Dev. Biol. 105, 435-442

10 Katagiri, C. (1987) Role of oviducal secretions in mediating gamete fusion in anuran amphibians. Zool. Sci. 4, 1-14

11 Arranz, S. E., Albertali, I. E. and Cabada, M. O. (1997) Bufo arenarum egg jelly coat: purification and characterization of two highly glycosylated proteins. Biochem. J. 323, 307-312

12 Strecker, G., Wieruszeski, J. M., Fontaine, M. D. and Plancke, Y. (1994) Structure of the major neutral oligosaccharide-alditols released from the egg jelly coats of Axolotl maculatum. Characterization of the carbohydrate sequence GalNAc( $\beta 1-4)[\mathrm{Fuc}(\alpha 1-3)] \operatorname{GlcNAc}(\beta 1-3 / 6)$. Glycobiology 4, 605-609

13 Strecker, G., Wieruszeski, J. M., Plancke, Y. and Boilly, B. (1995) Primary structure of 12 neutral oligosaccharide-alditols released from the jelly coats of the anuran Xenopus laevis by reductive $\beta$-elimination. Glycobiology 5, 137-146

14 Maes, E., Florea, D., Delplace, F., Lemoine, J., Plancke, Y. and Strecker, G. (1997) Structural analysis of the oligosaccharide-alditols released by reductive $\beta$-elimination from oviducal mucins of Rana temporaria. Glycoconjugate J. 14, 127-146

15 Morelle, W. and Strecker, G. (1997) Structural analysis of oligosaccharide-alditols released by reductive $\beta$-elimination from oviducal mucins of Bufo bufo: characterization of the carbohydrate sequence Gal ( $\alpha 1-3)$ GalNAc( $\alpha 1-3)[F u c(\alpha 1-2)]$ Gal. Glycobiology 7, 777-790

16 Morelle, W., Guyétant, R. and Strecker, G. (1998) Structural analysis of oligosaccharide-alditols released by reductive $\beta$-elimination from oviducal mucins of Rana dalmatina. Carbohydr. Res. 306, 435-443

17 Morelle, W. and Strecker, G. (1998) Structural analysis of a new series of oligosaccharide-alditols released by reductive $\beta$-elimination from oviducal mucins of Rana utricularia. Biochem. J. 330, 469-478

18 Morelle, W., Cabada, M. O. and Strecker, G. (1998) Structural analysis of oligosaccharide-alditols released by reductive $\beta$-elimination from the jelly coats of the anuran Bufo arenarum. Eur. J. Biochem. 252, 253-260

19 Maes, E., Florea, D., Coppin, A. and Strecker, G. (1999) Structural analysis of 20 oligosaccharide-alditols released from the jelly coat of Rana palustris eggs by reductive $\beta$-elimination. Characterization of the polymerized sequence $[\operatorname{Gal}(\beta 1-3) \operatorname{GalNAc}(\alpha 1-4)]_{n}$. Eur. J. Biochem. 264, 301-313

20 Varki, A. (1993) Biological roles of oligosaccharides: all of the theories are correct. Glycobiology 3, 97-130

21 Elinson, R. P. (1974) A block to cross-fertilization located in the egg jelly of the frog Rana clamitans. J. Embryol. Exp. Morphol. 32, 325-335

22 Kamerling, J. P., Gerwig, G. J., Vliegenthart, J. F. G. and Clamp, J. R. (1975) Characterization by gas-liquid chromatography - mass spectrometry and protonmagnetic-resonance spectroscopy of pertrimethylsilylmethylglycosides obtained in the methanolysis of glycoproteins and glycopeptides. Biochem. J. 151, 491-495

23 Ciucanu, I. and Kerek, F. (1984) A simple and rapid method for the permethylation of carbohydrates. Carbohydr. Res. 131, 209-217

24 Fournet, B., Strecker, G., Leroy, Y. and Montreuil, J. (1981) Gas-liquid chromatography and mass spectrometry of methylated and acetylated methyl glycosides. Application to the structural analysis of glycoprotein glycans. Anal. Biochem. 116, 489-502

25 Kamerling, J. P. and Vliegenthart, J. F. G. (1992) High-resolution ${ }^{1} \mathrm{H}$-nuclear magnetic resonance spectroscopy of oligosaccharide-alditols released from mucin-type 0glycoproteins. In Biological Magnetic Resonance, vol. 10 (Berliner, L. J. and Reben, J., eds.), pp. 1-194, Plenum Press, New York, NY

26 Morelle, W. and Strecker, G. (1997) Structural analysis of hexa to dodecaoligosaccharide-alditols released by reductive $\beta$-elimination from oviduca mucins of Bufo bufo. Glycobiology 7, 1129-1151 
27 Coppin, A., Maes, E., Flahaut, C., Coddeville, B. and Strecker, G. (1999) Acquisition of species-specific 0-linked carbohydrate chains from oviducal mucins in Rana arvalis. A case study. Eur. J. Biochem. 266, 370-382

28 Coppin, A., Maes, E., Morelle, W. and Strecker, G. (1999) Structural analysis of 13 neutral oligosaccharide-alditols released by reductive $\beta$-elimination from oviducal mucins of Rana temporaria. Eur. J. Biochem. 266, 94-104

29 Mourad, R., Morelle, W., Neveu, A. and Strecker, G. (2001) Diversity of O-linked glycosylation patterns between species. Characterization of 25 carbohydrate chains from oviducal mucins of Rana ridibunda. Eur. J. Biochem. 268, 1990-2003

30 Strecker, G., Wieruszeski, J. M., Michalski, J. C., Alonso, C., Leroy, Y., Boilly, B. and Montreuil, J. (1992) Primary structure of neutral and acidic oligosaccharide-alditols derived from the jelly coat of the Mexican axolotl. Occurrence of oligosaccharides

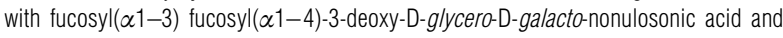
galactosyl( $\alpha 1-4)$ [fucosyl $(\alpha 1-2)$ ] galactosyl $(\beta 1-4)$ - $N$-acetylglucosamine sequences. Eur. J. Biochem. 207, 995-1002

31 Guerardel, Y., Kol, O., Maes, E., Lefebvre, T., Boilly, B., Davril, M. and Strecker, G. (2000) 0-glycan variability of egg-jelly mucins from Xenopus laevis: characterization of four phenotypes that differ by the terminal glycosylation of their mucins. Biochem. J. 352, 449-463

Received 20 July 2001/28 January 2002; accepted 18 February 2002
32 Strecker, G., Wieruszeski, J. M., Michalski, J. C., Alonso, C., Boilly, B. and Montreuil, J. (1992) Characterization of $\mathrm{Le}^{\mathrm{x}}$, $\mathrm{Le}^{\mathrm{y}}$ and $A L \mathrm{e}^{\mathrm{y}}$ antigen determinants in Kdncontaining 0 -linked glycan chains from Pleurodeles walt/ jelly coat eggs. FEBS Lett. 298, 39-43

33 Maes, E., Plancke, Y., Delplace, F. and Strecker, G. (1995) Primary structure of acidic oligosaccharide-alditols derived from the jelly coat of Ambystoma tigrinum. Occurrence of oligosaccharides with fucosyl( $\alpha 1-5)$ [fucosyl( $\alpha 1-4)]-3-d e o x y-D$ glycero-D-galacto-nonulosonic acid and fucosyl( $\alpha 1-2)$ galactosyl( $\alpha 1-3)-N$ acetylgalactosamine sequences. Eur. J. Biochem. 230, 146-156

34 Watkins, W. M. (1995) Molecular basis of antigenic specificity in the ABO, $\mathrm{H}$ and Lewis blood-group systems. In Glycoproteins (Montreuil, J, Vliegenthart, J. F. G. and Schachter, H., eds.), pp. 313-390, Elsevier, Oxford

35 Rasko, D. A., Wang, G., Monteiro, M. A., Palcic, M. M. and Taylor, D. E. (2000) Synthesis of mono- and di-fucosylated type I Lewis blood group antigens by Helicobacter pylori. Eur. J. Biochem. 267, 6059-6066

36 Suzuki, N., Khoo, K.-H., Chen, H.-C., Johnson, J. R. and Lee, Y. C. (2001) Isolation and characterization of major glycoproteins of pigeon egg white. Ubiquitous presence of unique N-glycans containing Gal $\alpha 1-4 \mathrm{Gal}$. J. Biol. Chem. 276, 23221-23229 